\title{
Análisis y elaboración de patrones morfológicos en la terminología médica: alemán-español
}

\author{
Beatriz Burgos Cuadrillero ${ }^{1}$ \\ Universidad de La Laguna
}

\author{
Kerstin I. Rohr Schrade \\ Universidad de La Laguna
}

\begin{abstract}
RESUMEN
La terminología médica procede, en su mayoría, del latín y del griego ya que, históricamente, estas lenguas fueron un vehículo de comunicación en el ámbito de la medicina. Por este motivo, los tecnicismos médicos han mantenido su univocidad mediante términos precisos que conservan su contenido semántico.

El tecnicismo grecolatino ofrece unas características óptimas para la terminología médica ya que mantiene la semántica de sus términos por tratarse de lenguas que no están subyugadas a cambios de significado. En la actualidad, conserva esta característica, de tal manera que "se trata de una terminología antigua, pero que se mantiene viva y, sobre todo, vinculante a nivel internacional"; sin embargo, "el principio de falta de ambigüedad se pierde en el lenguaje médico alemán debido, entre otros motivos, a la existencia de sinónimos o, también, de alternativas a los tecnicismos médicos en el lenguaje general" (Burgos Cuadrillero \& Rohr Schrade, 2016, p. 78). Así pues, la heterogénea designación que reciben los diferentes términos médicos dificulta, considerablemente, la creación de un lenguaje médico homogéneo.

Nuestro objetivo es profundizar y ampliar el análisis, desde el punto de vista contrastivo, de aquellas particularidades morfológicas de los diferentes procesos de formación de palabras en la terminología médica, con especial atención a la composición y a la derivación en lengua alemana y española. Se trata de elaborar una serie de patrones en el lenguaje médico para la comprensión de su terminología mediante el análisis y clasificación de sus tecnicismos según prefijos, sufijos y compuestos de dos y más constituyentes, tomando como punto de partida la lengua alemana y sus equivalentes en español.
\end{abstract}

Palabras claves: Terminología médica, composición y derivación, alemán-español

\footnotetext{
1 Corresponding author - Campus Universitario de Guajara, Facultad de Economía, Empresa y Turismo, apartado de correos 456, C.P. 38200, San Cristóbal de La Laguna (Tenerife) España.

E-mail: bburgosc@ull.edu.es.
} 


\begin{abstract}
Medical terminology derives mostly from Latin and Greek because historically these languages were the communication vehicle in the medical discipline. For this reason, medical technical terms have maintained their univocity thanks to precise terms that preserve their semantic content.

In keeping with this, Greco-Latin technicisms offer optimum characteristics for medical terminology because they maintain the semantics of their terms given that they are languages that are no longer subjected to changes of meaning. Currently, this characteristic remains in the sense that we are talking about old terminology, yet one that remains alive and, above all, internationally binding. However, the disambiguation principle does not always remain in German medical terminology due to, among other reasons, the existence of synonyms and, also, alternatives coming from the general languge but used as medical technicisms (vid. Burgos Cuadrillero \& Rohr Schrade, 2016, p. 78). The heterogeneous designation that the different medical terms receive makes it considerably difficult to create a homogeneous medical language.

The aim of this contribution is to study this phenomenon in depth. In addition, we want to extend the analysis, from a contrastive point of view, to the morphological peculiarities of the different processes of word formation in medical terminology, with special attention given to composition and to derivation both in German and Spanish. The purpose is to design different models in the medical language to understand its terminology analysing and classifying its technicisms based on prefixes, suffixes and compounds of two and more constituents, taking the German language as starting point and working out the equivalents in Spanish.
\end{abstract}

Keywords: Medical terminology, composition and derivation, German-Spanish

\title{
1. Introducción
}

La ciencia de la medicina presenta una marcada estratificación tanto a nivel horizontal como vertical. Por un lado, el plano horizontal engloba las diferentes disciplinas teóricas que muestran, a su vez, un fuerte grado de independencia tanto a nivel médico como lingüístico, independencia que puede generar problemas de comunicación en el campo de la medicina. Por otro lado, el lenguaje médico se divide en tres niveles en el plano vertical; esto es, el nivel científico que hace referencia a la comunicación entre científicos o entre científicos y médicos; el nivel que engloba al personal médico, es decir, la comunicación que se establece entre médicos, enfermeros y asistentes; y, por último, la comunicación entre médico y paciente.

El objetivo de nuestra contribución es profundizar y ampliar el análisis, desde el punto de vista contrastivo, de aquellas particularidades morfológicas de los diferentes procesos de formación de palabras en la terminología médica, con especial atención a la composición y a la derivación en lengua alemana y española. Se trata de elaborar una serie de patrones en el lenguaje médico para la comprensión de su terminología mediante el análisis y clasificación de sus tecnicismos según prefijos, sufijos y compuestos de dos y más constituyentes, tomando como punto de partida la lengua alemana y sus equivalentes en español. A este respecto, para la elaboración del 
corpus hemos tomado como referencia el alemán basándonos en el Wörterbuch medinizischer Fachbegriffe de la editorial Duden (2012) y sus correspondencias en el Diccionario de términos médicos de la Real Academia Nacional de Medicina (2012)2, prestando especial atención al lenguaje técnico y al uso de sinónimos en la lengua general de ambos idiomas.

El punto de partida para la recopilación de nuestro corpus es el WMF, aunque en un principio lo constituyó el DTM. El motivo radica en que el diccionario terminológico español ofrecía, a priori, una clasificación más unívoca de los diferentes constituyentes según compuestos y sufijos, mientras que en el diccionario alemán esta división era mucho más pormenorizada debido, entre otros motivos, a la complejidad que supone la formación de palabras en lengua alemana como, por ejemplo, la clasificación de algunos constituyentes según sufijos o sufijoides. La elección del WMF como fuente de referencia se basa en que, al recopilar los diferentes constituyentes prefijales, el DTM recogía en torno a diez compuestos y cuatro prefijos, mientras que en el WMF el número era mucho más elevado. Así pues, la elección del alemán como lengua de referencia se basa en la detallada clasificación que ofrece el WMF donde, como observaremos en el análisis realizado, se dividen los constituyentes en el ámbito de los compuestos según Wortbildungselement, Bestimmungswort, Grundwort o Zusammensetzung y en el campo de los derivados como Präfix o Vorsilbe y Suffix, Nachsilbe o Endung ${ }^{3}$.

Sin embargo, el diccionario terminológico alemán utiliza diferentes normas ortográficas a la hora de adaptar a la lengua alemana los términos grecolatinos e indica qué normas se deben aplicar para germanizar los tecnicismos. Si tomamos como ejemplo el término Caecum, observamos que los términos grecolatimos que comienzan por la letra c, se tienen que escribir con una k o una z (Caecum > Zäkum) para evitar una serie de términos híbridos como Caekum, Cäkum, Zaecum o Zäcum, es decir, el WMF recoge dos entradas como únicas alternativas correctas que son, por un lado, el término técnico grecolatino (Caecum) y, por otro lado, su germanización (Zäkum), recopilando la información, generalmente, bajo el lema germanizado. Además, como se puede observar en este mismo ejemplo, las secuencias vocálicas del latín como son ae/oe/ue se adaptan a la lengua alemana mediante la metafonía vocálica propia de este idioma (Umlaute) ä/ö/ü, tal y como expone Lippert (1999, p.1972):

Im Medizin-Duden 1992 findet man eindeutige Regeln für die Schreibweise, wonach z.B. lateinische Termini mit $c$ und deutsche Trivialbezeichnungen mit $k$ bzw. $z$ zu schreiben sind. Danach sind korrekte Formen Caecum (Blinddarm) und Zäkum. Häufig liest man aber auch Mischformen, wie Caekum, Cäkum, Zaecum, Zäcum, oder die veralteten Formen Coecum, Zökum usw. [...] Eine zusätzliche Schwierigkeit bietet die Uneinheitlichkeit der Einordnung der Umlaute in das Alphabet. Nach Duden werden die Umlaute $\ddot{a}, \ddot{o}, \ddot{u}$ und $\ddot{a} u$ wie die nicht umgelauteten Selbstlaute $a, o, u$, au behandelt,

\footnotetext{
${ }^{2}$ De aquí en adelante utilizaremos la abreviatura DTM para el diccionario en español y la abreviatura WMF para la versión alemana.

${ }^{3}$ En el análisis usaremos las siguientes abreviaturas: Wortbildungselement (WE), Bestimmungswort (BW), Grundwort (GW), Zusammensetzung (ZS), Präfix (P), Suffix (S), Vorsilbe (V), Nachsilbe (N) y Endung (E).
} 
dagegen $a e, o e$, ue wie die entsprechenden Buchstabenfolgen eingeordnet. Nach den ABC-Regeln von DIN5007 hingegen werden $\ddot{a}, \ddot{o}$ und $\ddot{u}$ wie $a e, o e$ und ue behandelt. Dies stört vor allem bei Umlauten am Wortanfang, z.B Ösophagus (Speiseröhre). ${ }^{4}$

\section{El lenguaje médico}

La terminología médica procede, en su mayoría, del latín y del griego, ya que, históricamente, estas lenguas fueron un vehículo de comunicación en el campo de la medicina, hecho que se ha mantenido hasta la actualidad, conservando así su univocidad. Además, el tecnicismo grecolatino ofrece unas características óptimas para la terminología médica ya que mantiene la semántica de sus términos por tratarse de lenguas que no están subyugadas a cambios de significado:

Eine tote Sprache bietet also den Vorteil, da $\beta$ der Wissenschaft Begriffe und Wörter mit konstanter Bedeutung zur Verfügung stehen, soweit nicht neue Erkentnisse in der Wissenschaft selbst einen Bedeutungswandel innerhalb der Wissenschaft herbeiführen. Denn nur der graeco-lateinische Ausdruck bietet dem Wissenschaftler jene eindeutige Präzision eines fest umrissenen Begriffs, die das angelsächsische Synonym fast stets vermissen läßt. (Michler \& Benedum, 1981, p. 5) ${ }^{5}$

En cuanto a la influencia de otras lenguas, el léxico médico cuenta, principalmente, con tres fuentes: los términos relativos a las enfermedades proceden del griego, los térmicos anatómicos (Nomina Anatomica) ${ }^{6}$ del latín y los neologismos del inglés

\footnotetext{
${ }^{4}$ En el Diccionario de Términos Médicos de la editorial Duden (1992) se recogen reglas unívocas para la ortografía, según las cuales se deben escribir los términos latinos con c y los términos triviales alemanes con $k$ o z. Por consiguiente, son formas correctas Caecum (apéndice) y Zäkum. Sin embargo, también se recogen a menudo formas mixtas como Caekum, Cäkum, Zaecum, Zäcum o las formas en desuso Coecum, Zökum, etc. [...] Una dificultad añadida es la falta de uniformidad en la clasificación de las diferentes metafonías vocálicas del alfabeto. Según el Duden, los cambios vocálicos ä ö, ü y äu son considerados como los sonidos vocálicos $a, o, u$, au; por el contrario, los sonidos $a e, o e$, ue aparecen en el orden alfabético correspondiente. Según las reglas del abecedario de DIN5007, coinciden $\ddot{a}$, ö y ü con ae, oe y ue. Esto dificulta, sobre todo, la metafonía vocálica a principio de palabra como, por ejemplo, Ösophagus (esófago).

${ }^{5}$ Una lengua muerta tiene la ventaja de poner a disposición de la ciencia conceptos y palabras con un significado fijo, siempre y cuando los avances científicos no conlleven un cambio de significado dentro de la especialidad. Solo la expresión grecolatina ofrece al científico una precisión inequívoca de un concepto definido de la que carece casi siempre el sinónimo anglosajón.

${ }^{6}$ A partir de 1895 se unificó la nomenclatura en el ámbito de la anatomía, recogiendo en torno a 6000 términos, con la finalidad de crear una única terminología a nivel internacional. Sus características son las siguientes:
}

- die Ein-Ein-Deutigkeit der Namensgebung (ein Begriff bezeichnet nur eine

Struktur; diese Struktur hat nur diesen einen Namen);

- die Vergabe der Namen in festgelegten Abständen überprüften Regeln;

- die Einigung auf Latein als Nomenklatursprache. (Karenberg, 2015, p. 22)

[- la falta de ambigüedad de la designación del concepto (un concepto sólo designa una estructura; esta estructura tiene solo una designación);

- la designación de los conceptos según reglas revisadas en periodos determinados; 
angloamericano, sobre todo, en aquellas especialidades médicas con una elevada y activa investigación, por ejemplo, la cirugía estética o la inmunología. No obstante, debemos también tener en cuenta que algunos términos proceden de otras lenguas como, por ejemplo, tecnicismos en el campo de la neurología que tienen su origen en lengua francesa (vid. Lippert, 1999, p. 1973).

Al tomar como ejemplo el término 'apendicitis', observamos que en lengua alemana se designa mediante diferentes tecnicismos, ya que recibe, por un lado, la denominación latina de appendicitis, por otro lado, la denominación germanizada de Appendizitis $y$, por último, la designación en el lenguaje general de Blinddarmentzündung ${ }^{7}$. Por lo tanto, podemos destacar que:

[...] se trata de una terminología antigua, pero que se mantiene viva y, sobre todo, vinculante a nivel internacional. Sin embargo, el principio de falta de ambigüedad se pierde en el lenguaje médico alemán debido, entre otros motivos, a la existencia de sinónimos o, también, de alternativas a los tecnicismos médicos en el lenguaje general. [...] Así pues, la lengua alemana carece de este principio por la heterogénea designación que reciben los diferentes términos médicos y que, a su vez, dificulta considerablemente la creación de un lenguaje homogéneo en el ámbito de la medicina. (Burgos Cuadrillero \& Rohr Schrade, 2016, p. 78)

\subsection{Características del lenguaje médico en lengua alemana}

Como ya hemos expuesto anteriormente, el plano vertical se divide en diferentes niveles. Por un lado, en el campo científico, los investigadores, médicos, profesores universitarios y estudiantes de medicina utilizan en mayor medida la terminología grecolatina como tradicional medio de comunicación; por otro lado, el personal médico en el ámbito de la praxis (médicos, enfermeros, personal biosanitario) conoce y utiliza los tecnicismos pertenecientes a su ámbito profesional, pero recurre, frecuentemente $y$ por comodidad, a tecnicismos germanizados (Trivialbezeichnungen/Trivialnamen); y, por último, en la comunicación entre médico y paciente, abundan términos de la lengua general alemana.

Al tener en cuenta que nuestro interés se centrará a lo largo de este análisis en los términos propios de la lengua alemana como sinónimos de los tecnicismos, nos gustaría hacer un pequeño inciso en cuanto a los términos triviales. Se trata de tecnicismos grecolatinos adaptados a la ortografía y fonética alemanas o, bien, a las reglas gramaticales de la lengua alemana:

Die meisten Trivialbezeichnungen sind eingedeutschte Fremdwörter, die nicht wie die Termini hinsichtlich einer sprachlich geforderten Informationsleistung genormt sind. Ihre äußere Form schwankt, ihr Begriffsinhalt ist häufig nicht einheitlich oder eindeutig definiert. (Duden,

- el acuerdo de establecer el latín como lengua para la nomenclatura.]

7 En este sentido, englobaremos estos términos bajo la designación de "alemán general" para diferenciarlo del alemán coloquial (Allgemeinsprache vs. Umgangsprache). 
2012, p. 26). ${ }^{8}$

En la siguiente tabla recogemos una serie de ejemplos donde se pueden observar diferentes procesos de germanización tanto a nivel ortográfico como gramatical':

\begin{tabular}{|c|c|c|}
\hline \multicolumn{3}{|c|}{ Nivel ortográfico } \\
\hline & Tecnicismo & Denominación trivial \\
\hline$c>z$ & $\begin{array}{l}\text { Fascia (axillaris) } \\
\text { cerebralis }\end{array}$ & $\begin{array}{l}\text { Faszie } \\
\text { zerebral }\end{array}$ \\
\hline$c>k$ & $\begin{array}{l}\text { Acne (vulgaris) } \\
\text { Caries (dentium) }\end{array}$ & $\begin{array}{l}\text { Akne } \\
\text { Karies }\end{array}$ \\
\hline oe > ö & Oesophagus & Ösophagus \\
\hline$a e>a ̈$ & Haemophilus & Hämophilus \\
\hline \multicolumn{3}{|c|}{ Nivel gramatical } \\
\hline & Tecnicismo & Denominación trivial \\
\hline -oma > -om & Carcinoma & Karzinom \\
\hline -ia > -ie & Anaemia & Anämie \\
\hline -ae > -en & $\begin{array}{l}\text { Concha } \rightarrow \text { pl. Conchae } \\
\text { Appendicitis (acuta) } \rightarrow \text { pl. } \\
\text { Appendicitides (acutae) }\end{array}$ & $\begin{array}{l}\text { Koncha } \rightarrow \text { pl. Konchen } \\
\text { Appendizitis } \rightarrow \text { pl. Appendizitiden }\end{array}$ \\
\hline
\end{tabular}

Tabla I. Procesos de germanización a nivel ortográfico y gramatical.

\section{Modelos estructurales: la composición y la derivación como principales procesos de formación de palabras en la terminología médica}

En lengua alemana hay varios procesos de formación de palabras destacando, por su importancia y frecuencia, la composición y la derivación. El resultado de estos procesos son términos que contribuyen a la precisión y la economía lingüística en el lenguaje médico, importantes características del lenguaje especializado. En el caso de la lengua alemana, la formación de palabras representa, en la terminología médica, un patrón más productivo en comparación con otras lenguas y cubre la demanda de conceptos en los lenguajes de especialidad:

Innerhalb der Fachsprachen des Deutschen stellt die erhöhte Ausschöpfung bestimmter Wortbildungsmöglichkeiten [sic] ein auffälliges Merkmal dar. Für solch häufige Wortbildungen im fachsprachlichen Bereich sind mindestens zwei allgemeine Gründe anzuführen: Zum einen hat das Deutsche als eine Sprache zu gelten, deren Wortbildungsbereich im Vergleich zu anderen Sprachen auch ausserhalb fachsprachlicher Äußerungen verhältnismäßig produktiv ist. Und zum

\footnotetext{
${ }^{8}$ La mayoría de las designaciones triviales son palabras extranjeras germanizadas que, en comparación con los términos técnicos, carecen de un significado fijo. Su significante no está normalizado y, a menudo, su significado carece de uniformidad.

${ }^{9}$ Los ejemplos son tomados del WMF.

${ }^{10}$ El WMF clasifica también como Trivialbezeichnung aquellos tecnicismos de nomenclaturas compuestas que se simplifican en un solo término.
} 
anderen kann mit dieser für das Deutsche also charakteristischen grammatischen Konstruktionsweise dem erhöhten Benennungsbedarf im Rahmen fachlicher Kommunikation leicht Genüge getan werden. Im einzelnen wird dabei sowohl auch die Möglichkeiten der Komposition als auch auf diejenigen der Derivation sowie der Kürzung und der Konversion zurückgegriffen. (Roelcke, 1999, p. 73) ${ }^{11}$

Estas características, propias de la lengua alemana, no las comparten las lenguas romances, como es el caso del español, porque en lugar de generar un término en el lenguaje médico, predominan otros procesos como son la formación de grupos de palabras, hecho que ha llevado a algunos autores a plantear la hipótesis de si se trata de denominaciones que representan un concepto o son, más bien, paráfrasis explicativas (vid. Arntz\&Picht, 1995, pp. 149-151).

Desde el punto de vista morfológico, tanto las formaciones de palabras prefijales como sufijales se clasifican en dos grandes grupos, según tengan un sinónimo en la lengua general o no. La mayoría de los términos médicos en lengua alemana disponen de un tecnicismo de origen grecolatino y de otro término en el lenguaje general. Sin embargo, el español cuenta, en muy raras ocasiones, con un sinónimo en el lenguaje general, como podemos observar en las tablas que exponemos a continuación, aunque con frecuencia recurre a sinónimos que son, a su vez, tecnicismos del ámbito medico.

La lengua alemana hace uso también de otros recursos en el lenguaje general como son, por ejemplo, sintagmas formados por un sustantivo acompañado de uno o varios adjetivos, recurso que también utiliza el español, paráfrasis con genitivo, complementos preposicionales, el uso del participio, tanto de presente como de pasado, o la transformación mediante una oración de relativo o de infinitivo.

\section{Análisis de los constituyentes prefijales}

\subsection{Constituyentes compositivos en posición prefijal ${ }^{12}$}

Uno de los grupos más productivos es el formado por aquellos términos con un sinónimo en el alemán general ${ }^{13}$. Se trata de constituyentes compositivos prefijales que pueden presentar desde una variante (adeno-) hasta cuatro (dermato-/dermat/dermo-/derm-) y cuentan con un sinónimo en la lengua común como, por ejemplo, Drüsenerweichung para el término 'Adenomalazie'.

\footnotetext{
${ }^{11}$ Una característica llamativa de las lenguas especializadas en alemán es recurrir, cada vez más, a determinadas formaciones de palabras, fundamentalmente, por dos motivos: por un lado, el alemán se considera una lengua que, en comparación con otras, es también bastante productiva en formación de palabras fuera del ámbito de las lenguas especializadas. Por otro lado, la formación de palabras cubre, en el ámbito del lenguaje especializado, la alta demanda de generar denominaciones. En particular, se recurre tanto a la composición como a la derivación, así como a la abreviación y a la conversión.

${ }^{12}$ En el WMF está registrado también el constituyente compositivo prefijal pico- (piko-) (BW) pero no está ejemplarizado con ningún término.

${ }^{13} \mathrm{Vid}$. a este respecto el Apéndice I.
} 
A este respecto, el DTM no recoge todos los términos, aunque sí se registran en páginas web relacionadas con el ámbito de la medicina como, por ejemplo, 'adenomalacia'. Estos términos no cuentan, por norma general, con un sinónimo en el español común aunque, en ocasiones, el diccionario registra sinónimos bajo la denominación de "coloquial" como son, por ejemplo, "ataque cardiaco" para el término 'infarto de miocardio' o el sinónimo “ojos” para 'oftalmología'.

Algunos constituyentes compositivos en posición prefijal cuentan con un complemento en genitivo en el alemán general ${ }^{14}$ o con un sintagma nominal formado por uno o varios adjetivos15. Con respecto a las correspondencias en español, se trata de constituyentes que siguen el mismo patrón que los anteriores, es decir, el DTM no recoge algunos términos aunque sí aparecen en diferentes páginas web del ámbito médico, por ejemplo, 'hipnalgia' y las correspondencias en el español general forman parte, de nuevo, del campo de la medicina.

Asimismo, otros constituyentes cuentan con un sintagma formado por un participio de presente o de pasado en el alemán común, generalmente, mediante el participio de presente:

\begin{tabular}{|c|c|c|c|c|}
\hline Compuesto & Alemán médico & $\begin{array}{l}\text { Alemán } \\
\text { general }\end{array}$ & $\begin{array}{l}\text { Español } \\
\text { médico }\end{array}$ & $\begin{array}{l}\text { Español } \\
\text { médico/general }\end{array}$ \\
\hline $\begin{array}{l}\text { audio- (audi-) } \\
\text { (WE) }\end{array}$ & auditiv (auditivus) & $\begin{array}{l}\text { das Gehör } \\
\text { betreffend }\end{array}$ & Auditivo & Acústico \\
\hline geo- (WE) & geophil (ADJ) & $\begin{array}{l}\text { vorzugsweise in } \\
\text { Erde und Staub } \\
\text { vorkommend }\end{array}$ & & \\
\hline geronto- (WE) & gerontologisch & $\begin{array}{l}\text { die } \\
\text { Gerontologie } \\
\text { betreffend }\end{array}$ & Gerontológico & $\begin{array}{l}\text { De la gerontología } \\
\text { o relacionado con } \\
\text { ella }\end{array}$ \\
\hline $\begin{array}{l}\text { haplo- (hapl-) } \\
\text { (BW) }\end{array}$ & haploid & $\begin{array}{l}\text { nur mit einem } \\
\text { einfachen } \\
\text { Chromosomens } \\
\text { atz ausgestattet }\end{array}$ & Haploide & $\begin{array}{l}\text { Haplobionte, } \\
\text { monoploide, } \\
\text { monoplonte }\end{array}$ \\
\hline infra- (ZS) & $\begin{array}{l}\text { infraorbital } \\
\text { (infraorbitalis) }\end{array}$ & $\begin{array}{l}\text { unterhalb der } \\
\text { Augenhöle } \\
\text { gelegen }\end{array}$ & Infraorbital & $\begin{array}{l}\text { Infraorbitario, } \\
\text { suborbitario }\end{array}$ \\
\hline kryo- (WE) & kryophil & Kälte liebend & Criófilo & $\begin{array}{l}\text { Psicrófilo: que } \\
\text { tiene apetencia } \\
\text { por las bajas } \\
\text { temperaturas }\end{array}$ \\
\hline onko- (WE) & onkogen & $\begin{array}{l}\text { einen Tumor } \\
\text { erzeugend }\end{array}$ & Oncógeno & Tumorígeno \\
\hline pluri- (WE) & $\begin{array}{l}\text { pluriglandulär } \\
\text { (pluriglandularis) }\end{array}$ & $\begin{array}{l}\text { mehrere } \\
\text { Drüsen }\end{array}$ & Pluriglandular & $\begin{array}{l}\text { Poliglandular, } \\
\text { multiglandular: de }\end{array}$ \\
\hline
\end{tabular}

${ }^{14}$ Vid. a este respecto el Apéndice II.

${ }^{15}$ Vid. a este respecto el Apéndice III. 


\begin{tabular}{ll}
\hline betreffend & $\begin{array}{l}\text { varias glándulas o } \\
\text { relacionado con } \\
\text { ellas }\end{array}$ \\
\hline
\end{tabular}

Tabla II. Constituyentes compositivos en posición prefijal con un sintagma formado por un participio de presente o de pasado en el alemán general.

En otras ocasiones, los constituyentes compositivos en posición prefijal cuentan con un complemento preposicional en lengua alemana mediante las preposiciones von, im o aus, entre otras. A este respecto, la lengua española genera, de nuevo, términos del ámbito médico:

\begin{tabular}{|c|c|c|c|c|}
\hline Compuesto & $\begin{array}{l}\text { Alemán } \\
\text { médico }\end{array}$ & Alemán general & $\begin{array}{l}\text { Español } \\
\text { médico }\end{array}$ & $\begin{array}{l}\text { Español } \\
\text { médico/genera } \\
\text { I }\end{array}$ \\
\hline allo- (all-) (WE) & Alloplastik & $\begin{array}{l}\text { Verwendung von } \\
\text { körperfremden, } \\
\text { künstlichen } \\
\text { Materialen bei } \\
\text { plastischen } \\
\text { Operationen }\end{array}$ & Aloplastia & Alotrasplante \\
\hline $\begin{array}{l}\text { chemo- (chemi-, } \\
\text { chem-) (WE) }\end{array}$ & Chemotherapie & $\begin{array}{l}\text { Behandlung von } \\
\text { Infektionskrankh } \\
\text { eiten mit } \\
\text { chemotherapeuti } \\
\text { schen Mitteln }\end{array}$ & Quimioterapia & $\begin{array}{l}\text { Farmacoterapia, } \\
\text { terapia } \\
\text { farmacológica }\end{array}$ \\
\hline $\begin{array}{l}\text { chrono- (chron-) } \\
\text { (WE) }\end{array}$ & $\begin{array}{l}\text { Chronoquimiot } \\
\text { erapia }\end{array}$ & $\begin{array}{l}\text { Verabreichung } \\
\text { von } \\
\text { Chemotherapeuti } \\
\text { ka in } \\
\text { Abhängigkeit von } \\
\text { der Tageszeit } \\
\end{array}$ & & \\
\hline $\begin{array}{l}\text { histo- (hist-, } \\
\text { histio-) (BW) }\end{array}$ & Histologie & $\begin{array}{l}\text { wissenschaftliche } \\
\text { Lehre von den } \\
\text { Körpergeweben } \\
\text { der Lebewesen }\end{array}$ & Histología & $\begin{array}{l}\text { Anatomía } \\
\text { microscópica }\end{array}$ \\
\hline $\begin{array}{l}\text { hyalo- (hyal-) } \\
\text { (BW) }\end{array}$ & Hyalomukoid & $\begin{array}{l}\text { schleimartige } \\
\text { Substanz im } \\
\text { Glaskörper des } \\
\text { Auges }\end{array}$ & & \\
\hline $\begin{array}{l}\text { ovo- (ovi-, ov-) } \\
\text { (BW) }\end{array}$ & Ovotestis & $\begin{array}{l}\text { Zwitterorgan aus } \\
\text { Hoden- u. } \\
\text { Eierstocksgewebe }\end{array}$ & Ovotestis & Ovotestículo \\
\hline
\end{tabular}

Tabla III. Constituyentes compositivos en posición prefijal con un complemento preposicional en el alemán general.

Por último, algunos constituyentes presentan una oración de relativo en el alemán general como, por ejemplo, human- o tri-: 


\begin{tabular}{|c|c|c|c|c|}
\hline Compuesto & $\begin{array}{l}\text { Alemán } \\
\text { médico }\end{array}$ & Alemán general & $\begin{array}{l}\text { Español } \\
\text { médico }\end{array}$ & $\begin{array}{l}\text { Español } \\
\text { médico/general }\end{array}$ \\
\hline human- (WE) & $\begin{array}{l}\text { Humanmedizi } \\
\mathrm{n}\end{array}$ & $\begin{array}{l}\text { die eigentliche Medizin, } \\
\text { die sich ausschließlich } \\
\text { auf den Menschen } \\
\text { erstreckt; im Gegesatz } \\
\text { zur Tiermedizin }\end{array}$ & & \\
\hline tri- (BW) & Trisomie & $\begin{array}{l}\text { Auftreten eines } \\
\text { überzähligen } \\
\text { Chromosoms, das im } \\
\text { diploiden } \\
\text { Chromosomensatz } \\
\text { nicht zweimal, sondern } \\
\text { dreimal vorkommt }\end{array}$ & Trisomía & \\
\hline
\end{tabular}

Tabla IV. Constituyentes compositivos en posición prefijal con una oración de relativo en el alemán general.

\subsection{Prefijos $^{16}$}

En el plano morfológico, el grupo más productivo es el formado por aquellos términos en el alemán médico con un sinónimo en el alemán general ${ }^{17}$. Algunos términos del español médico no están recogidos en el DTM, aunque sí se pueden encontrar en páginas web del ámbito de la medicina como, por ejemplo, 'heterotermo' o 'parodontosis', términos que, de nuevo, no suelen presentar un sinónimo en el español común.

Algunos prefijos generan términos con un complemento preposicional en el alemán general o con un sintagma formado por un participio de presente o de pasado como podemos observar en las siguientes tablas:

\begin{tabular}{lllll}
\hline Prefijo & $\begin{array}{l}\text { Alemán } \\
\text { médico }\end{array}$ & Alemán general & $\begin{array}{l}\text { Español } \\
\text { médico }\end{array}$ & $\begin{array}{l}\text { Español } \\
\text { médico/general }\end{array}$ \\
\hline extra- $(\mathrm{P})$ & $\begin{array}{l}\text { extradural } \\
\text { (extraduralis) }\end{array}$ & $\begin{array}{l}\text { außerhalb der } \\
\text { harten Hirnhaut } \\
\text { gelegen }\end{array}$ & Extradural & Epidural \\
\hline intra- (P) & intraalveolär & $\begin{array}{l}\text { innerhalb der } \\
\text { Lungenbläschen; } \\
\text { innerhalb der } \\
\text { Zahnfächer }\end{array}$ & & \\
\hline per- (V) & perkutan & $\begin{array}{l}\text { durch die Haut } \\
\text { hindurch }\end{array}$ & Percutáneo & $\begin{array}{l}\text { Transcutáneo, } \\
\text { transdérmico }\end{array}$ \\
\hline
\end{tabular}

\footnotetext{
${ }^{16}$ En el WMF está también registrado como prefijo el constituyente out- en términos como Outcome, Outlet o Output. En este sentido, no lo hemos incluido en el análisis por generar tecnicismos en lengua inglesa.

${ }^{17}$ Vid. a este respecto el Apéndice IV.
} 


\begin{tabular}{|c|c|c|c|c|}
\hline supra- (P) & $\begin{array}{l}\text { suprarrenal } \\
\text { (suprarrenalis) }\end{array}$ & oberhalb der Niere & Suprarrenal & $\begin{array}{l}\text { Situado o que } \\
\text { tiene lugar por } \\
\text { encima del riñón }\end{array}$ \\
\hline
\end{tabular}

Tabla V. Prefijos con un complemento preposicional en el alemán general.

\begin{tabular}{lllll}
\hline Prefijo & $\begin{array}{l}\text { Alemán } \\
\text { médico }\end{array}$ & Alemán general & $\begin{array}{l}\text { Español } \\
\text { médico }\end{array}$ & $\begin{array}{l}\text { Español } \\
\text { médico/general }\end{array}$ \\
\hline anti- (ant-) (P) & antibakteriell & $\begin{array}{l}\text { gegen Bakterien } \\
\text { wirksam od. } \\
\text { gerichtet }\end{array}$ & Antibacteriano & Antibiótico \\
\hline bi- (bin-) (P) & $\begin{array}{l}\text { binaural } \\
\text { (binauralis) }\end{array}$ & $\begin{array}{l}\text { beide Ohren } \\
\text { betreffend }\end{array}$ & Binaural & $\begin{array}{l}\text { Biauricular: de los } \\
\text { dos oídos o } \\
\text { relacionado con } \\
\text { ellos }\end{array}$ \\
\hline exo- (P) & exogen & $\begin{array}{l}\text { außerhalb des } \\
\text { Organismus } \\
\text { entstehend }\end{array}$ & Exógeno & $\begin{array}{l}\text { Extrínseco, } \\
\text { xenógeno }\end{array}$ \\
& & $\begin{array}{l}\text { durch Noradrenalin } \\
\text { bewirkt }\end{array}$ & $\begin{array}{l}\text { Noradrenérgic } \\
\text { o }\end{array}$ & $\begin{array}{l}\text { Que libera } \\
\text { noradrenalina }\end{array}$ \\
\hline nor- (V) & noradrenerg & & &
\end{tabular}

Tabla VI. Prefijos con un sintagma formado por un participio de presente o de pasado en el alemán general.

Otros prefios como son ekto- o prä- tienen su correspondencia en el alemán general mediante un sintagma nominal formado por uno o varios adjetivos o el caso del prefijo pan- mediante una oración de relativo:

\begin{tabular}{lllll}
\hline Prefijo & $\begin{array}{l}\text { Alemán } \\
\text { médico }\end{array}$ & Alemán general & $\begin{array}{l}\text { Español } \\
\text { médico }\end{array}$ & $\begin{array}{l}\text { Español } \\
\text { médico/general }\end{array}$ \\
\hline $\begin{array}{l}\text { ekto- (ecto-) } \\
\text { (P) }\end{array}$ & Ektoderm & $\begin{array}{l}\text { äußere Hautschicht } \\
\text { des tierischen und } \\
\text { menschlichen } \\
\text { Keimes }\end{array}$ & Ectodermo & Ectoblasto \\
& & & \\
\hline $\begin{array}{l}\text { prä- (prae-, } \\
\text { pre-) (P) }\end{array}$ & Prämolar & $\begin{array}{l}\text { vorderer, } \\
\text { zweihöckeriger } \\
\text { Backenzahn }\end{array}$ & Premolar & Diente premolar \\
\hline
\end{tabular}

Tabla VII. Prefijos con un sintagma nominal formado por uno o varios adjetivos en el alemán general.

\begin{tabular}{|c|c|c|c|c|}
\hline Prefijo & $\begin{array}{l}\text { Alemán } \\
\text { médico }\end{array}$ & Alemán general & $\begin{array}{l}\text { Español } \\
\text { médico }\end{array}$ & $\begin{array}{l}\text { Español } \\
\text { médico/general }\end{array}$ \\
\hline pan- $(P)$ & Panarthritis & $\begin{array}{l}\text { Gelenkentzündung, } \\
\text { die alle Teile eines } \\
\text { Gelenks } \\
\text { einschließlich der } \\
\text { umgebenden } \\
\text { Gewebe erfasst }\end{array}$ & Panartritis & $\begin{array}{l}\text { Inflamación de } \\
\text { una articulación } \\
\text { con afectación } \\
\text { simultánea de } \\
\text { todos los } \\
\text { elementos que la } \\
\text { forman: huesos, } \\
(\ldots)\end{array}$ \\
\hline
\end{tabular}


Tabla VIII. Prefijos con una oración de relativo en el alemán general.

\section{Análisis de los constituyentes sufijales}

\subsection{Constituyentes compositivos en posición sufijal}

Uno de los grupos más amplios lo forman aquellos constituyentes con un sinónimo en el alemán general ${ }^{18} \mathrm{y}$, desde el punto de vista morfológico, destacan por su productividad -algie, -loge y -pathie. Por un lado, el constituyente -algie genera series de palabras en el lenguaje general donde la palabra determinante es una parte del cuerpo y la palabra base es el término "Schmerz" (Magenschmerz); por otro lado, el constituyente sufijal -loge genera compuestos cuya palabra base es el término "Arzt" (Augenarzt) y, con respecto a -pathie, se trata de un constituyente sufijal que genera términos con la palabra base "Leiden" o "Krankheit" (Magenleiden).

En cuanto al español médico, la mayoría de los términos alemanes encuentran su correspondencia en el DTM y solo en contadas ocasiones se recoge un sinónimo del español general, por ejemplo, "oculista" para el término 'oftalmólogo', ya que, generalmente, se trata de términos del ámbito de la medicina.

Asimismo, otro de los grupos es el que contiene aquellos constituyentes con un sintagma formado por un participio de presente o de pasado en el alemán común ${ }^{19}$. A este respecto, la mayoría de las correspondencias se realizan mediante un participio de presente y en el español común se trata, generalmente, de términos del campo médico.

En el apartado de los constituyentes compositivos en posición sufijal, destacan también otros grupos, aunque menos productivos, como, por ejemplo, los que generan en la lengua común una oración de relativo o de infinitivo:

\begin{tabular}{|c|c|c|c|c|}
\hline Compuesto & $\begin{array}{l}\text { Alemán } \\
\text { médico }\end{array}$ & Alemán general & $\begin{array}{l}\text { Español } \\
\text { médico }\end{array}$ & $\begin{array}{l}\text { Español } \\
\text { médico/genera } \\
\text { I }\end{array}$ \\
\hline -ergie (WE) & Energie & $\begin{array}{l}\text { Fähigkeit eines Körpers, } \\
\text { Arbeit zu leisten }\end{array}$ & Energía & $\begin{array}{l}\text { Magnitud física } \\
\text { que representa } \\
\text { la capacidad de } \\
\text { un sistema para } \\
\text { producir trabajo }\end{array}$ \\
\hline $\begin{array}{l}\text {-gramm } \\
\text { (GW) }\end{array}$ & Engramm & $\begin{array}{l}\text { bleibende } \\
\text { Gedächtnisspur, die ein } \\
\text { Reiz im } \\
\text { Zentralnervensystem } \\
\text { hinterlässt }\end{array}$ & Engrama & Huella mnémica \\
\hline -nomie (WE) & Ergonomie & $\begin{array}{l}\text { Teilbereich der } \\
\text { Arbeitsphysiologie, der } \\
\text { sich mit den }\end{array}$ & Ergonomía & \\
\hline
\end{tabular}

${ }^{18}$ Vid. a este respecto el Apéndice $V$.

${ }^{19} \mathrm{Vid}$. a este respecto el Apéndice VI. 


\begin{tabular}{|c|c|c|c|c|}
\hline & & $\begin{array}{l}\text { Möglichkeiten einer } \\
\text { Anpassung der Arbeit an } \\
\text { den Menschen befasst }\end{array}$ & & \\
\hline -phage (GW) & $\begin{array}{l}\text { Bakteriopha } \\
\text { ge }\end{array}$ & $\begin{array}{l}\text { Viren, deren Wirte } \\
\text { Bakterien sind, inserieren } \\
\text { ihre Nukleinsäuren ins } \\
\text { Bakteriengenom } \\
\text { (temperente Phagen) } \\
\text { oder zerstören nach } \\
\text { zellinterner Vermehrung } \\
\text { die Bakterien (virulente } \\
\text { Phagen) }\end{array}$ & Bacteriófago & Virus bacteriano \\
\hline
\end{tabular}

Tabla IX. Constituyentes compositivos en posición sufijal con una oración de relativo o de infinitivo en el alemán general.

Otros constituyentes sufijales como -skopie y -stomie generan una paráfrasis mediante un complemento en genitivo; otro grupo es el formado por los constituyentes -grafie y -tropie con correspondencias en el alemán general mediante un sintagma adjetival $y$, por último, se encuentra el constituyente -graf que genera un complemento preposicional. En el caso de la lengua española, se trata de términos médicos que, en ocasiones, no se registran en el DTM y que encuentran, de nuevo, un sinónimo en el español médico como observamos en las siguientes tablas:

\begin{tabular}{lllll}
\hline Compuesto & $\begin{array}{l}\text { Alemán } \\
\text { médico }\end{array}$ & Alemán general & $\begin{array}{l}\text { Español } \\
\text { médico }\end{array}$ & $\begin{array}{l}\text { Español } \\
\text { médico/genera } \\
\text { I }\end{array}$ \\
\hline -skopie (WE) & Gastroskopie & $\begin{array}{l}\text { Untersuchung des } \\
\text { Mageninneren mit } \\
\text { dem Gastroskop }\end{array}$ & Gastroscopia & $\begin{array}{l}\text { Endoscopia } \\
\text { gástrica }\end{array}$ \\
\hline -stomie (WE) & $\begin{array}{l}\text { Gastroduodeno } \\
\text { stomie }\end{array}$ & $\begin{array}{l}\text { operative Herstellung } \\
\text { einer (künstlichen) } \\
\text { Verbindung zwischen } \\
\text { Magen und } \\
\text { Zwölffingerdarm }\end{array}$ & $\begin{array}{l}\text { Gastroduode } \\
\text { nostomía }\end{array}$ & $\begin{array}{l}\text { Anastomosis } \\
\text { gastroduodenal }\end{array}$ \\
& & & & \\
& & & & \\
\hline
\end{tabular}

Tabla X. Constituyentes compositivos en posición sufijal con un complemento en genitivo en el alemán general.

\begin{tabular}{|c|c|c|c|c|}
\hline Compuesto & $\begin{array}{l}\text { Alemán } \\
\text { médico }\end{array}$ & Alemán general & $\begin{array}{l}\text { Español } \\
\text { médico }\end{array}$ & $\begin{array}{l}\text { Español } \\
\text { médico/general }\end{array}$ \\
\hline $\begin{array}{l}\text {-grafie (- } \\
\text { graphie) (GW) }\end{array}$ & Arteriografie & $\begin{array}{l}\text { röntgenografische } \\
\text { Darstellung einer } \\
\text { Arterie bzw. des } \\
\text { arteriellen } \\
\text { Gefäßsystems nach } \\
\text { Kontrastmittelfüllun } \\
\text { g }\end{array}$ & Arteriografía & $\begin{array}{l}\text { Angiografía } \\
\text { arterial }\end{array}$ \\
\hline -tropie (GW) & Androtropie & Auftreten einer & & \\
\hline
\end{tabular}


Krankheit nur oder

vorwiegend beim

männlichen

Geschlecht

Tabla XI. Constituyentes compositivos en posición sufijal con un sintagma nominal formado por uno o varios adjetivos en el alemán general.

\begin{tabular}{lllll}
\hline Compuesto & $\begin{array}{l}\text { Alemán } \\
\text { médico }\end{array}$ & Alemán general & $\begin{array}{l}\text { Español } \\
\text { médico }\end{array}$ & $\begin{array}{l}\text { Español } \\
\text { médico/general }\end{array}$ \\
\hline -graf (-graph) & Elektrokymogra & Apparat zur & & \\
(GW) & $\mathrm{f}$ & $\begin{array}{l}\text { Durchführung der } \\
\text { Elektrokymografie }\end{array}$ & \\
\hline
\end{tabular}

Tabla XII. Constituyentes compositivos en posición sufijal con un complemento preposicional en el alemán general.

\subsection{Sufijos}

En cuanto a los sufijos, el grupo más amplio es el constituido por aquellos con un sinónimo en el alemán general ${ }^{20}$ y destacan por su alta productividad los sufijos -itis y $-o m$.

El constituyente -itis genera sinónimos con la palabra base "Entzündung" ('Angiitis' = Blutgefäßentzündung) y, en ocasiones, el tecnicismo tiene una correspondencia en el alemán general mediante un complemento en genitivo ('Hepatitis' = Entzündung der Leber). En español, este sufijo puede generar un sinónimo en el lenguaje general como, por ejemplo, "anginas" para el tecnicismo ' amigdalitis', pero frecuentemente recurre al sintagma preposicional "inflamación de" ('Hepatitis' = "inflamación del hígado").

En segundo lugar, se encuentra el sufijo -om (-oma) que genera sinónimos en el lenguaje general ('Angiom' = Blutschwamm). Como podemos observar, el significado más común del sufijo -om/-oma es el de "tumor", pero puede significar, en otras ocasiones, el resultado de un proceso como, por ejemplo, el término 'Glaukom' (Glaucoma), con correspondencias en la lengua general tanto alemana (grüner Star) como española (catarata verde) (vid. Burgos Cuadrillero \& Rohr Schrade, 2016, p. 81).

En el grupo de los sufijos destacan también otros grupos como el formado por los constituyentes -path e -yl que generan correspondencias en el alemán general mediante un complemento preposicional encabezado por diferentes preposiciones al formar la paráfrasis como son, entre otras, mit o aus y con correspondencias en el español médico, pero con ausencia de sinónimos en la lengua común como observamos a continuación:

${ }^{20}$ Vid. a este respecto el Apéndice VII. 


\begin{tabular}{lllll}
\hline Sufijo & $\begin{array}{l}\text { Alemán } \\
\text { médico }\end{array}$ & Alemán general & $\begin{array}{l}\text { Español } \\
\text { médico }\end{array}$ & $\begin{array}{l}\text { Español } \\
\text { médico/general }\end{array}$ \\
\hline -path (S) & Psychopath & $\begin{array}{l}\text { Mensch mit schweren } \\
\text { Persönlichkeitsstörung } \\
\text { en mit antisozialen } \\
\text { Verhaltensmustern }\end{array}$ & Psicópata & \\
& & & \\
\hline -yl (N) & Methyl & einwertiges Radikal aus & Metilo & Radical \\
& & einem Kohlenstoffatom & & $\begin{array}{l}\text { uvivalente del } \\
\text { metano, de } \\
\end{array}$ \\
& & fórmula química \\
& Wasserstoffatomen & & $-\mathrm{CH}$ [Abr.: Me] \\
\hline
\end{tabular}

Tabla XIII. Sufijos con un complemento preposicional en el alemán general.

En este apartado también se recogen sufijos en el alemán médico con correspondencias en el alemán general mediante un sintagma formado por un participio de presente o de pasado como es el caso del sufijo - $a$ l, mediante un sintagma nominal formado por uno o varios adjetivos con el sufijo -iase o con correspondencias en la lengua común mediante una oración de relativo a través del sufijo -ase, generando, de nuevo, sinónimos en el español médico:

\begin{tabular}{lllll}
\hline Sufijo & Alemán médico & Alemán general & $\begin{array}{l}\text { Español } \\
\text { médico }\end{array}$ & $\begin{array}{l}\text { Español } \\
\text { médico/general }\end{array}$ \\
\hline -al (-ell) (S) & hormonal & aus Hormonen & Hormonal & $\begin{array}{l}\text { De las hormonas } \\
\text { o relacionado } \\
\text { (hormonell) }\end{array}$ \\
& & bestehend & & \\
\hline
\end{tabular}

Tabla XIV. Sufijos con un sintagma formado por un participio de presente o de pasado en el alemán general.

\begin{tabular}{lllll}
\hline Sufijo & $\begin{array}{l}\text { Alemán } \\
\text { médico }\end{array}$ & Alemán general & $\begin{array}{l}\text { Español } \\
\text { médico }\end{array}$ & $\begin{array}{l}\text { Español } \\
\text { médico/general }\end{array}$ \\
\hline -iase $/-$ & $\begin{array}{l}\text { Helminthiasis } \\
\text { iasis (E) }\end{array}$ & $\begin{array}{l}\text { durch } \\
\text { (Helminthose) }\end{array}$ & $\begin{array}{l}\text { Eingeweidewürme } \\
\text { r hervorgerufene } \\
\text { Wurmkrankheit }\end{array}$ & Verminosis \\
& & & \\
\hline
\end{tabular}

Tabla XV. Sufijos con un sintagma nominal formado por uno o varios adjetivos en el alemán general.

\begin{tabular}{|c|c|c|c|c|}
\hline Sufijo & Alemán médico & Alemán general & $\begin{array}{l}\text { Español } \\
\text { médico }\end{array}$ & $\begin{array}{l}\text { Español } \\
\text { médico/general }\end{array}$ \\
\hline -ase (E) & $\begin{array}{l}\text { Protease } \\
\text { (Proteinase, } \\
\text { Peptidase, } \\
\text { proteolytische } \\
\text { Enzyme) }\end{array}$ & $\begin{array}{l}\text { Enzyme, die } \\
\text { Peptidbindungen } \\
\text { in Proteine und } \\
\text { Peptide spalten } \\
\text { (Proteolyse), man } \\
\text { unterscheidet } \\
\text { Endo- und } \\
\text { Exopeptidasen }\end{array}$ & Proteinasa & $\begin{array}{l}\text { Peptidasa: } \\
\text { enzima } \\
\text { proteolítica, } \\
\text { hidrolasa } \\
\text { peptídica }\end{array}$ \\
\hline
\end{tabular}

Tabla XVI. Sufijos con una oración de relativo en el alemán general. 


\section{Conclusiones}

A modo de conclusión, podemos destacar que tanto la composición como la derivación son procedimientos muy productivos en el lenguaje médico alemán, motivo por el cual el conocimiento de sus patrones morfológicos supone una gran ayuda para conocer el significado del tecnicismo, al tiempo que simplifica el aprendizaje del lenguaje especializado en lenguas extranjeras.

En cuanto a la terminología médica, la lengua alemana general dispone de un mayor número de sinónimos que la española y los sinónimos registrados en español no son comprensibles, en su mayoría, por los profanos, recogiendo el DTM sólo en contadas ocasiones bajo la denominación de "coloquial" términos frecuentes y entendibles en el español general. En otras ocasiones, los tecnicismos se corresponden en el lenguaje general alemán con complementos en genitivo, con complementos preposicionales, con sintagmas nominales formados por uno o varios adjetivos, con sintagmas formados por el participio de presente o de pasado o con oraciones de relativo o de infinitivo.

Así mismo, hay términos registrados en el diccionario terminológico alemán WMF que, por el contrario, no encuentran su equivalencia en el DTM, incluyendo este último diccionario otras denominaciones en español que no están tan intrínsecamente relacionadas con el campo médico como es, por ejemplo, el término 'rímel'. También debemos destacar que algunos términos en lengua alemana no están registrados en el diccionario específico Wörterbuch medizinischer Fachbegriffe, pero sí tienen una entrada en diccionarios de uso general como, por ejemplo, el tecnicismo 'Arthrose' con sinónimos en el lenguaje común (Gelenkverschleiß), la designación Gelenkversteifung para el término médico 'Ankylose' o el término Zucker, muy extendido en el lenguaje general.

En el WMF se recogen las entradas de la terminología médica mediante el tecnicismo grecolatino y a través de su término germanizado, recopilando la información, generalmente, bajo el lema germanizado, excepto los términos anatómicos que se registran, en su mayoría, por su forma grecolatina ('Antebrachium', 'Mesencephalon', 'Myelencephalon'). A diferencia del diccionario especializado en lengua alemana, en el DTM se recogen los lemas bajo el término en español con su correspondencia en lengua inglesa.

Según el corpus analizado, el número de constituyentes prefijales, tanto compuestos como prefijos, es superior al de los constituyentes sufijales, pero estos últimos elementos generan patrones más productivos que en el campo prefijal. Los constituyentes sufijales se dividen en dos grupos: constituyentes sustantivales y adjetivales, ya que el sufijo, a diferencia del prefijo, determina la categoría gramatical de la palabra. Los compuestos sustantivales en posición sufijal analizados se refieren a diferentes categorías médicas como son, entre otras, síntomas de enfermedades mediante el sufijo -algie, procedimientos instrumentales a través de compuestos con el sufijo -gramm o diferentes aspectos relacionados con la disciplina de la medicina con el constituyente -logie. Los sinónimos en el alemán general tienen, en la mayoría de las ocasiones, como palabra determinante un sustantivo y están formados, 
generalmente, por dos constituyentes.

En el campo de los compuestos sufijales destaca, especialmente, el constituyente algie por ser muy productivo en lengua alemana. Este compuesto genera series de términos en el lenguaje general donde la palabra determinante es una parte del cuerpo y la palabra base es el término "Schmerz" (Magenschmerz, Gelenkschmerz, Hautnervenschmerz, Muskelschmerz, Nervenschmerz, Ohrenschmerz). En lengua española, las correspondencias se realizan mediante un sintagma nominal acompañado por un adjetivo ("dolor estomacal") o a través de un complemento de nombre ("dolor de estómago").

Asímismo, otros compuestos sufijales que generan patrones morfológicos en la lengua alemana general son -lith con la palabra base "Stein" (Gallenstein, Darmstein, Kotstein), -loge cuya palabra base es "Arzt" (Augenarzt, Nervenarzt) y el constituyente pathie con la palabra base "Leiden" o "Krankheit" (Magenleiden, Gefäßleiden, Blutkrankheit).

Con respecto a los sufijos, estos constituyentes se pueden agrupar, entre otros, según enfermedades especiales (-itis, -oma, -osis) o materias o sustancias (-ase) y, al igual que los compuestos en posición sufijal, cuentan con un sinónimo en la lengua común alemana. En este campo debemos destacar el sufijo -itis por ser altamente productivo y a través del cual se forman derivados técnicos en alemán cuya raíz es una parte del cuerpo, con sus correspondientes sinónimos en la lengua general mediante la palabra base "Entzündung" (Mandelentzündung, Blutgefäßentzündung, Tränendrüsenentzündung, Hautentzündung, Dünndarmentzündung, Eierstockentzündung). Las correspondencias de este sufijo en lengua española son derivados en -itis como, por ejemplo, el tecnicismo 'amigdalitis' con sinónimos en la lengua común ("anginas"), pero, a diferencia de la lengua alemana, se trata de un sufijo que no sigue un patrón morfológico productivo ya que, normalmente, genera sinónimos mediante el complemento de nombre "inflamación de".

Del mimo modo, otros sufijos que dan lugar a series de palabras, aunque no de forma tan productiva, son -om y -meter y, en el ámbito adjetival, destaca en lengua alemana el sufijo -id, generando sinónimos con la palabra base "ähnlich", es decir, se trata de formaciones que designan una forma y denotan el parecido con algo (drüsenähnlich, schleimähnlich).

\section{About the author}

Beatriz Burgos Cuadrillero es licenciada en Filología Alemana por la Universidad de Valladolid donde trabajó como personal investigador en formación y profesora asociada, concluyendo allí su doctorado. Posteriormente desempeñó su función docente e investigadora en la Rheinische Friedrich-Wilhelms-Universtät Bonn y actualmente es Profesor Ayudante Doctor en la Universidad de La Laguna. Sus principales líneas de investigación giran en torno a la lingüística aplicada y contrastiva (alemán-español) así como a la didáctica del alemán como lengua 
extranjera (DaF).

Kerstin I. Rohr Schrade, Catedrática de E.U, se licenció (1982) y se doctoró (1986) en Filología Germánica y Románica por la Karls- Ruprecht-Universität Heidelberg (Alemania). Desde 1987 imparte, entre otras, alemán en el ámbito empresarial y turístico en la Facultad de Economía, Empresa y Turismo de la Universidad de La Laguna. Su actividad investigadora gira en torno a la didáctica del alemán para fines específicos, a la lingüística aplicada así como a la lexicología.

\section{LFE Article history}

Paper received: $1^{\text {st }}$ September 2016

Paper received in revised form and accepted for publication: 20 ${ }^{\text {th }}$ February 2017

\section{Bibliografía}

Arntz, R. \& Picht, H. (1995). Introducción a la terminología. Madrid: Fundación Germán Sánchez Ruipérez.

Burgos Cuadrillero, B. \& Rohr Schrade, K. (2016). Estudio contrastivo de la terminología médica alemán-español mediante los diferentes procesos de formación de palabras (Wortbildung). In M.F. Litzler, J. García Laborda \& C. Tejedor Martínez (Eds.), Beyond the universe of Languages for Specific Purposes: The 21st century perspective (pp. 77-83). Alcalá de Henares: Servicio de Publicaciones de la Univesidad de Alcalá.

Duden (2012). Wörterbuch medizinischer Fachbegriffe (9a ed.). Berlin: Dudenverlag.

Fluck, H. R. (1991). Fachsprachen (4a ed.). Tübingen: Francke Verlag.

Karenberg, A. (2015). Fachsprache Medizin im Schnellkurs für Studium und Berufspraxis (4a ed.). Freiburg: Schattauer.

Lippert, H.(1999). Die Fachlexikographie der Medizin: Ein Übersicht. In L. Hoffmann, H. Kalverkämper \& H. E. Wiegand (Eds.), Fachsprachen/Languages for Special Purposes. Ein internationales Handbuch zur Fachsprachenforschung und Terminologiewisssenschaft (pp. 1966-1975). Berlin y New York: Walter de Gruyter.

Merkelbach, C. (2012). Anforderungen für den fremdsprachigen Fachsprachenunterricht am Beispiel der medizinischen Fachsprache. 淡江外語論丵, 19, 103-148.

Michler, M. \& Benedum, J. (1981). Einführung in die medizinische Fachsprache. Medizinische Terminologie für Mediziner und Zahnmediziner auf der Grundlage des Lateinischen und Griechischen ( $2^{\mathrm{a}}$ ed.). Berlin-Heidelberg y New York: Springer.

Real Academia Nacional de Medicina (2012). Diccionario de términos médicos. Madrid: Médica Panamericana. 
Roelcke, T. (1999). Fachsprachen. Berlin: Erich Schmidt Verlag.

\section{Apéndice I}

\begin{tabular}{|c|c|c|c|c|}
\hline Compuesto & Alemán médico & Alemán general & $\begin{array}{l}\text { Español } \\
\text { médico }\end{array}$ & $\begin{array}{l}\text { Español } \\
\text { médico/genera } \\
\text { I }\end{array}$ \\
\hline adeno- (BW) & $\begin{array}{l}\text { Adenomalazie } \\
\text { (Adenomalacia) }\end{array}$ & Drüsenerweichung & & \\
\hline aero- (aer-) (WE) & aerogen & gasbildend & Aerógeno & \\
\hline \multirow[t]{2}{*}{ akro-(akr-) (WE) } & $\begin{array}{l}\text { Akrozephalie } \\
\text { (Acrocephalia) }\end{array}$ & Hochköpfigkeit & Acrocefalia & Oxicefalia \\
\hline & $\begin{array}{l}\text { Akrenzephalon = } \\
\text { Telencephalon } \\
\text { (Telenzephalon) }\end{array}$ & Endhirn & Telencéfalo & $\begin{array}{l}\text { Vesícula } \\
\text { telencefálica }\end{array}$ \\
\hline andro- (WE) & Andrologie & Männerheilkunde & Andrología & \\
\hline angio- (angi-) (WE) & $\begin{array}{l}\text { Angiopathie } \\
\text { (Angiopathia) }\end{array}$ & Gefäßleiden & Angiopatía & \\
\hline ante- (ZS) & Antebrachium & Unterarm & Antebrazo & \\
\hline $\begin{array}{l}\text { arthro- (arthr-) } \\
\text { (BW) }\end{array}$ & Arthrodese & Gelenkverödung & Artrodesis & $\begin{array}{l}\text { Anquilosis } \\
\text { artificial }\end{array}$ \\
\hline anthropo- (WE) & Anthropologie & Menschenkunde & Antropología & \\
\hline auto- (aut-) (WE) & Autohämotherapie & Eigenblutbehandlung & $\begin{array}{l}\text { Autohemotera } \\
\text { pia }\end{array}$ & Autotransfusión \\
\hline $\begin{array}{l}\text { bio- (-biont, - } \\
\text { biose) (WE) }\end{array}$ & $\begin{array}{l}\text { Biorheuse } \\
\text { (Biorrheuse) }\end{array}$ & Lebensfluss & Biorritmo & Biociclo \\
\hline blasto- (BW) & $\begin{array}{l}\text { Blastomyzet } \\
\text { (Blastomyces) }\end{array}$ & Sprosspilz, Hefepilz & Blastomiceto & \\
\hline brachy- (WE) & brachyzephal & $\begin{array}{l}\text { kurzköpfig, } \\
\text { rundschädelig }\end{array}$ & Braquicéfalo & \\
\hline $\begin{array}{l}\text { blepharo- } \\
\text { (blephar-) (BW) }\end{array}$ & $\begin{array}{l}\text { Blepharoklonus } \\
\text { (Blepharospasmus) }\end{array}$ & Augenlidkrampf & $\begin{array}{l}\text { Blefaroespas } \\
\text { mo }\end{array}$ & Blefarismo \\
\hline $\begin{array}{l}\text { cheiro- (cheir-, } \\
\text { chir-, chir(o)-) } \\
\text { (BW) }\end{array}$ & Cheirospasmus & Schreibkrampf & & \\
\hline $\begin{array}{l}\text { chloro- (chlor-) } \\
\text { (WE) }\end{array}$ & Chlorophyll & Blattgrün & & \\
\hline $\begin{array}{l}\text { chole- (cholo-, } \\
\text { chol-) (WE) }\end{array}$ & Choledocholithiasis & $\begin{array}{l}\text { Gallengangssteinleide } \\
\mathrm{n}\end{array}$ & $\begin{array}{l}\text { Coledocolitiasi } \\
\mathrm{s}\end{array}$ & \\
\hline $\begin{array}{l}\text { chondro- } \\
\text { (chondri-, chondr- } \\
\text { ) (BW) }\end{array}$ & $\begin{array}{l}\text { Chondromalazie } \\
\text { (Chondromalacia) }\end{array}$ & Knorpelerweichung & $\begin{array}{l}\text { Condromalaci } \\
\text { a }\end{array}$ & \\
\hline $\begin{array}{l}\text { chromo- } \\
\text { (chromato-, } \\
\text { chrom-, chromat- }\end{array}$ & Chromatopsie & Farbigsehen & Cromatopsia & $\begin{array}{l}\text { Visión de los } \\
\text { colores }\end{array}$ \\
\hline
\end{tabular}




\begin{tabular}{|c|c|c|c|c|}
\hline$)(B W)$ & & & & \\
\hline $\begin{array}{l}\text { dakryo- (dakry-, } \\
\text { dacry(o)-) (BW) }\end{array}$ & $\begin{array}{l}\text { Dakryorrhö } \\
\text { (Dakryorrhöe, } \\
\text { Dacryorrhoea) } \\
\end{array}$ & Tränenfluss & Dacriorrea & Lagrimeo \\
\hline $\begin{array}{l}\text { daktylo- (dactylo-) } \\
\text { (BW) }\end{array}$ & Daktylogramm & Fingerabdruck & Dactilograma & Huella dactilar \\
\hline $\begin{array}{l}\text { dermato- } \\
\text { (dermat-, dermo-, } \\
\text { derm-) (WE) }\end{array}$ & Dermografismus & Hautschrift & $\begin{array}{l}\text { Dermografism } \\
\text { o }\end{array}$ & Dermografía \\
\hline $\begin{array}{l}\text { desmo- (desm-) } \\
\text { (BW) }\end{array}$ & Desmokranium & Bindegewebsschädel & & \\
\hline $\begin{array}{l}\text { deutero- (deuter-, } \\
\text { deuto-, deut-) } \\
\text { (BW) }\end{array}$ & Deuter[o]anopie & $\begin{array}{l}\text { Rotgrünblindheit } \\
\text { (Form der } \\
\text { Farbenblindheit) }\end{array}$ & Deuteranopía & \\
\hline diplo- (dipl-) (BW) & Diplopie & Doppelsehen & Diplopia & Visión doble \\
\hline $\begin{array}{l}\text { dolicho- (dolich-) } \\
\text { (BW) }\end{array}$ & Dolichozephalie & Langschädel & Dolicocefalia & Escafocefalia \\
\hline $\begin{array}{l}\text { entero- (enter-) } \\
\text { (WE) }\end{array}$ & Enterolith & Darmstein & Enterolito & $\begin{array}{l}\text { Cálculo } \\
\text { intestinal }\end{array}$ \\
\hline $\begin{array}{l}\text { erythro- (erythr-) } \\
\text { (BW) }\end{array}$ & Erythrochloropie & Blaugelbblindheit & & \\
\hline $\begin{array}{l}\text { foto- (fot-, photo-) } \\
\text { (WE) }\end{array}$ & Fototherapie & Lichtheilverfahren & Fototerapia & Actinoterapia \\
\hline $\begin{array}{l}\text { galakto- (galakt-) } \\
\text { (WE)21 }\end{array}$ & $\begin{array}{l}\text { Galaktorrhö } \\
\text { (Galaktorrhöe, } \\
\text { Galactorrhoea) }\end{array}$ & Milchfluss & Galactorrea & Lactorrea \\
\hline $\begin{array}{l}\text { gastro- (gastr-) } \\
\text { (WE) }\end{array}$ & Gastrorrhaphie & Magennaht & Gastrorrafia & Sutura gástrica \\
\hline $\begin{array}{l}\text { glyko- (glyk-, } \\
\text { glyc[o]-) (BW) }\end{array}$ & Glykokoll & Leimsüß & Glicocola & Glicina \\
\hline gynäko- (WE) & Gynäkophobie & Weiberscheu & Ginecofobia & Ginofobia \\
\hline $\begin{array}{l}\text { hämato- (hämat-, } \\
\text { haemat[o]-) (WE) }\end{array}$ & $\begin{array}{l}\text { Hämatopoese } \\
\text { (Hämatose, } \\
\text { Hämopoese) } \\
\end{array}$ & Blutbildung & Hematosis & \\
\hline \multirow[t]{2}{*}{$\begin{array}{l}\text { hämo- (häm-, } \\
\text { haem[o]-) (WE) }\end{array}$} & $\begin{array}{l}\text { Hämarthrose } \\
\text { (Haemarthrosis) }\end{array}$ & Blutergelenk & Hemartrosis & Hemartros \\
\hline & Hämopathie & $\begin{array}{l}\text { Blutkrankheit, } \\
\text { Blutleiden }\end{array}$ & Hemopatía & \\
\hline $\begin{array}{l}\text { heliko- (helico-) } \\
\text { (BW) }\end{array}$ & Helicotrema & Schneckenloch & Helicotrema & $\begin{array}{l}\text { Hiato de } \\
\text { Breschet }\end{array}$ \\
\hline hemi- (BW) & Hemianop[s]ie & $\begin{array}{l}\text { Halbsichtigkeit, } \\
\text { Halbseitenblindheit }\end{array}$ & Hemianopsia & Hemianopía \\
\hline $\begin{array}{l}\text { homöo- (homö-) } \\
\text { (BW) }\end{array}$ & homöomorph & gleichgestaltig & & \\
\hline $\begin{array}{l}\text { hydro- (hydr-, } \\
\text { hyd-, hydato-) } \\
\text { (WE) }\end{array}$ & $\begin{array}{l}\text { Hydroperikard } \\
\text { (Hydropericardium } \\
\text { ) }\end{array}$ & Herzwassersucht & $\begin{array}{l}\text { Hidropericardi } \\
\text { o }\end{array}$ & \\
\hline hystero- (hyster-) & Hysterotomie & Gebärmutterschnitt & Histerotomía & Cesárea \\
\hline
\end{tabular}

${ }^{21}$ El mismo significado tiene el constituyente lakto- (WE): inlaktieren, Laktoflavin, Laktose. 


\begin{tabular}{|c|c|c|c|c|}
\hline (BW) & & & & \\
\hline idio- (WE) & Idiophorie & Vererbung & & \\
\hline $\begin{array}{l}\text { kardio- (kardi-) } \\
\text { (WE) }\end{array}$ & Kardiopathie & $\begin{array}{l}\text { Herzleiden, } \\
\text { Herzerkrankung }\end{array}$ & Cardiopatía & $\begin{array}{l}\text { Enfermedad } \\
\text { cardiaca }\end{array}$ \\
\hline karzino- (WE) & Karzinogenese & Krebsentstehung & $\begin{array}{l}\text { Carcinogénesi } \\
\text { s }\end{array}$ & Cancerogénesis \\
\hline kata- (kat-) (ZS) & Katarrh (Catarrhus) & $\begin{array}{l}\text { Schleimhautentzündu } \\
\text { ng (mit meist } \\
\text { reichlichen } \\
\text { Absonderungen) }\end{array}$ & Catarro & \\
\hline $\begin{array}{l}\text { kolpo- (kolp-) } \\
\text { (BW) }\end{array}$ & Kolpotomie & Scheidenschnitt & & \\
\hline $\begin{array}{l}\text { kopro- (kopr-) } \\
\text { (BW) }\end{array}$ & Koprolith & Kotstein & Coprolito & Fecalito \\
\hline $\begin{array}{l}\text { krypto- (krypt-) } \\
\text { (WE) }\end{array}$ & Kryptorchismus & $\begin{array}{l}\text { Bauchhoden oder } \\
\text { Leistenhoden }\end{array}$ & Criptorquismo & $\begin{array}{l}\text { Criptorquidismo } \\
\text { [Coloq22.: } \\
\text { testículo no } \\
\text { descendido] }\end{array}$ \\
\hline laparo- (BW) & Laparotomie & Bauchschnitt & Laparonomía & $\begin{array}{l}\text { Incisión } \\
\text { abdominal }\end{array}$ \\
\hline lepto- (BW) & Leptoprosopie & Schmalgesichtigkeit & & \\
\hline leuko- (leuk-) (WE) & leukoderm & $\begin{array}{l}\text { hellhäutig, } \\
\text { pigmentarm }\end{array}$ & & \\
\hline lipo- (lip-) (BW) & Lipödem & $\begin{array}{l}\text { Fettgewebsvermehrun } \\
\mathrm{g}\end{array}$ & & \\
\hline litho- (lith-) (WE) & Lithopädion & Steinkind & Litopedion & Feto calcinado \\
\hline logo- (WE) & Logopädie & Sprachheilkunde & Logopedia & $\begin{array}{l}\text { Patología del } \\
\text { lenguaje }\end{array}$ \\
\hline $\begin{array}{l}\text { makro- (makr-, } \\
\text { macr[o]-) (WE) }\end{array}$ & makrozephal & großköpfig & Macrocéfalo & Megacéfalo \\
\hline $\begin{array}{l}\text { masto- (mast-) } \\
\text { (BW) }\end{array}$ & Mastoptose & Brustsenkung & & \\
\hline $\begin{array}{l}\text { mega- (meg, } \\
\text { megalo-, megal-) } \\
\text { (WE) }\end{array}$ & Megakaryozyt & $\begin{array}{l}\text { Knochenmarksriesenz } \\
\text { ellen }\end{array}$ & Megacariocito & \\
\hline $\begin{array}{l}\text { melano- (melan-) } \\
\text { (BW) }\end{array}$ & melanoderm & dunkelhäutig & & \\
\hline mero- (BW) & merokrin & teilsezernierend & Merocrino & \\
\hline meso- (mes-) (WE) & Mesencephalon & Mittelhirn & Mesencéfalo & Cerebro medio \\
\hline $\begin{array}{l}\text { mikro- (mikr-, } \\
\text { micro-) (WE) }\end{array}$ & mikrozephal & kleinköpfig & Microcefálico & Microcéfalo \\
\hline $\begin{array}{l}\text { myelo- (myel-) } \\
\text { (BW) }\end{array}$ & $\begin{array}{l}\text { Myelencephalon } \\
\text { (Myelenzephalon) }\end{array}$ & Nachhirn, Markhirn & Mielencéfalo & \\
\hline $\begin{array}{l}\text { myko- (myk-, } \\
\text { myc[o]-) (BW) }\end{array}$ & Mykose (Mycosis) & Pilzerkrankung & Micosis & $\begin{array}{l}\text { Infección por } \\
\text { hongos }\end{array}$ \\
\hline
\end{tabular}

${ }^{22}$ Abreviatura que utiliza el DTM con el significado de "coloquialmente". 


\begin{tabular}{|c|c|c|c|c|}
\hline myo- (my-) (WE) & Myokardinfarkt & Herzinfarkt & $\begin{array}{l}\text { Infarto de } \\
\text { miocardio }\end{array}$ & $\begin{array}{l}\text { Infarto cardiaco } \\
\text { [Coloq.: ataque } \\
\text { cardíaco, } \\
\text { ataque al } \\
\text { corazón] }\end{array}$ \\
\hline $\begin{array}{l}\text { myxo- (myx-) } \\
\text { (BW) }\end{array}$ & Myxoid & schleimähnlich & Mixoide & Muciforme \\
\hline $\begin{array}{l}\text { nekro- (nekr-, } \\
\text { necr[o]-) (BW) }\end{array}$ & Nekropsie & $\begin{array}{l}\text { Totenschau, } \\
\text { Leichenschau }\end{array}$ & Necropsia & Autopsia \\
\hline neo- (ne-) (WE) & Neoplasma & $\begin{array}{l}\text { echte } \\
\text { Gewebsneubildung }\end{array}$ & Neoplasma & Tumor \\
\hline $\begin{array}{l}\text { nephro- (nephr-) } \\
\text { (BW) }\end{array}$ & Nephrorrhagie & Nierenblutung & & \\
\hline $\begin{array}{l}\text { neuro- (neuri-, } \\
\text { neur-) (WE) }\end{array}$ & $\begin{array}{l}\text { Neuralgie } \\
\text { (Neuralgia) }\end{array}$ & Nervenschmerz & Neuralgia & Dolor periférico \\
\hline noso- (nos-) (BW) & Nosografie & $\begin{array}{l}\text { Krankheitsbeschreibu } \\
\text { ng }\end{array}$ & Nosografía & Patografía \\
\hline $\begin{array}{l}\text { nykto- (nykt-) } \\
\text { (BW) }\end{array}$ & Nyktalgie & Nachtschmerz & & \\
\hline $\begin{array}{l}\text { odonto- (odont-) } \\
\text { (BW) }\end{array}$ & Odontalgie & Zahnschmerz & Odontalgia & $\begin{array}{l}\text { Dolor de } \\
\text { muelas }\end{array}$ \\
\hline öko- (WE) & Ökotrophologie & $\begin{array}{l}\text { Haushalts- und } \\
\text { Ernährungswissensch } \\
\text { aft }\end{array}$ & & \\
\hline oligo- (olig-) (WE) & Oligohydramnie & Fruchtwassermangel & $\begin{array}{l}\text { Oligohidramni } \\
\text { os }\end{array}$ & Oligoamnios \\
\hline $\begin{array}{l}\text { onycho- (onych-) } \\
\text { (BW) }\end{array}$ & Onychoschisis & Nagelspaltung & Onicosis & Onicopatía \\
\hline o०- (BW) & oophorus & Eitragend & & \\
\hline $\begin{array}{l}\text { ophthalmo- } \\
\text { (ophthalm-) (BW) }\end{array}$ & Ophthalmiatrik & Augenheilkunde & Oftalmología & Coloq: ojos \\
\hline ortho- (orth-) (WE) & orthozephal & rechtköpfig & & \\
\hline oto- (ot-) (BW) & Otoplastik & Ohrpassstück & Otoplastia & \\
\hline pädo- (päd-) (WE) & Pädiatrie & Kinderheilkunde & Pediatría & \\
\hline $\begin{array}{l}\text { patho- (path-) } \\
\text { (WE) }\end{array}$ & Pathothesaurose & Speicherkrankheit & & \\
\hline pharmako- (WE) & Pharmakognosie & Drogenkunde & $\begin{array}{l}\text { Farmacognosi } \\
\text { a }\end{array}$ & \\
\hline $\begin{array}{l}\text { phlebo- (phleb-) } \\
\text { (BW) }\end{array}$ & $\begin{array}{l}\text { Phlebektasie } \\
\text { (Phelbectasia) }\end{array}$ & Venenerweiterung & Flebectasia & Variz \\
\hline $\begin{array}{l}\text { phono- (fono-, } \\
\text { phon-, fon-) (WE) }\end{array}$ & Phonmanie & Mordsucht & Fonomanía & $\begin{array}{l}\text { Síndorme } \\
\text { Amok, locura } \\
\text { homicida } \\
\end{array}$ \\
\hline $\begin{array}{l}\text { physio- (physic-, } \\
\text { phys-) (WE) }\end{array}$ & Physiotherapie & Naturheilbehandlung & Fisioterapia & Terapia física \\
\hline phyto- (phyt-) & Phytotherapie & Pflanzenheilkunde & Fitoterapia & \\
\hline
\end{tabular}




\begin{tabular}{|c|c|c|c|c|}
\hline (WE) & & & & \\
\hline platy- (plat-) (WE) & Platyzephalus & $\begin{array}{l}\text { Flachkopf (niedriger } \\
\text { Schädel) }\end{array}$ & & \\
\hline pleo- (pleio-) (WE) & Pleochromismus & $\begin{array}{l}\text { Mehrfarbigkeit (je } \\
\text { nach der } \\
\text { Einfallrichtung des } \\
\text { Lichtes } \\
\text { unterschiedliche } \\
\text { Färbung) }\end{array}$ & & \\
\hline poly- (WE) & Polymorphismus & Vielgestaltigkeit & Polimorfismo & Pleomorfismo \\
\hline $\begin{array}{l}\text { prosopo- } \\
\text { (prosop-) (WE) }\end{array}$ & Prosoposchisis & Gesichtsspalte & & \\
\hline proto- (prot-) (WE) & Protanopie & Rotblindheit & & \\
\hline $\begin{array}{l}\text { pseudo- (pseud-) } \\
\text { (WE) }\end{array}$ & Pseudoanämie & $\begin{array}{l}\text { Scheinanämie, } \\
\text { Scheinblutarmut }\end{array}$ & $\begin{array}{l}\text { Pseudoanemi } \\
\text { a }\end{array}$ & \\
\hline $\begin{array}{l}\text { psycho- (psych-) } \\
\text { (WE) }\end{array}$ & $\begin{array}{l}\text { Psychochromästhe } \\
\text { sie }\end{array}$ & Farbenhören & & \\
\hline pyelo- (pyel-) (WE) & Pyelolith & Nierenbeckenstein & & \\
\hline pyo- (py-) (WE) & Pyodermie & Eiterausschlag & Piodermia & $\begin{array}{l}\text { Dermatitis } \\
\text { purulenta }\end{array}$ \\
\hline radio- (WE) & Radiotherapie & Strahlenbehandlung & Radioterapia & Actinoterapia \\
\hline retro- (WE) & retrograd & $\begin{array}{l}\text { rückläufig, } \\
\text { rückwirkend }\end{array}$ & Retrógrado & \\
\hline rhino- (rhin-) (WE) & $\begin{array}{l}\text { Rhinencephalon } \\
\text { (Rhinenzephalon) }\end{array}$ & Riechhirn & Rinencéfalo & Área olfatoria \\
\hline schizo- (WE) & schizophren & spaltungsirre & Esquizofrénico & \\
\hline semi- (WE) & $\begin{array}{l}\text { semilunar } \\
\text { (semilunaris) }\end{array}$ & halbmondförmig & Semilunar & \\
\hline $\begin{array}{l}\text { sklero- (skler-, } \\
\text { scler[o]-) (WE) }\end{array}$ & Skleradenitis & Drüsenverhärtung & & \\
\hline spheno- (WE) & $\begin{array}{l}\text { sphenoidalis } \\
\text { (sphenoideus) }\end{array}$ & keilförmig & Esfenoideo & Esfenoidal \\
\hline stereo- (WE) & stereoskopisch & $\begin{array}{l}\text { räumlich, } \\
\text { dreidimensional, } \\
\text { körperlich }\end{array}$ & $\begin{array}{l}\text { Estereoscópic } \\
\text { o }\end{array}$ & Tridimensional \\
\hline stomato- (WE) & Stomatoschisis & Hasenscharte & Queilosquisis & Labio leporino \\
\hline tachy- (BW) & Tachypnoe & Kurzatmigkeit & Taquipnea & $\begin{array}{l}\text { Polipnea, } \\
\text { respiración } \\
\text { acelerada }\end{array}$ \\
\hline $\begin{array}{l}\text { thermo- (therm-) } \\
\text { (WE) }\end{array}$ & Thermoplegie & Hitzschlag & & \\
\hline $\begin{array}{l}\text { thyreo- (thyro-) } \\
\text { (BW) }\end{array}$ & thyreoideus & schildförmig & Tiroideo & \\
\hline topo- (top-) (BW) & Topophobie & Ortsangst & & \\
\hline
\end{tabular}




\begin{tabular}{|c|c|c|c|c|}
\hline $\begin{array}{l}\text { toxic[o]-, toxi-, } \\
\text { toxo-, tox-) (BW) }\end{array}$ & Toxikomanie & Medikamentensucht & Toxicomanía & Drogadicción \\
\hline $\begin{array}{l}\text { tricho- (trich-) } \\
\text { (BW) }\end{array}$ & Trichogramm & Haarbild & & \\
\hline trocho- (BW) & Trochozephalus & $\begin{array}{l}\text { Rundkopf, } \\
\text { Rundschädel }\end{array}$ & & \\
\hline $\begin{array}{l}\text { xantho- (xanth-) } \\
\text { (WE) }\end{array}$ & xanthoderm & gelbhäutig & & \\
\hline $\begin{array}{l}\text { zephalo- (zephal-, } \\
\text { cephal-) (WE) }\end{array}$ & Zephalhämatom & Kopfblutgeschwulst & $\begin{array}{l}\text { Cefalohemato } \\
\text { ma }\end{array}$ & \\
\hline \multirow[t]{2}{*}{$\begin{array}{l}\text { zirkum- (circum-) } \\
\text { (WE) }\end{array}$} & $\begin{array}{l}\text { zirkumskript } \\
\text { (circumscriptus) }\end{array}$ & $\begin{array}{l}\text { umschrieben (deutlich } \\
\text { abgegrenzt) }\end{array}$ & Circunscrito & \\
\hline & circumflexus & $\begin{array}{l}\text { umgebogen, } \\
\text { bogenförmig }\end{array}$ & Circunflejo & \\
\hline ZOO- (WE) & Zoonose & Tierseuche & Zoonosis & \\
\hline $\begin{array}{l}\text { zyano- (zyan-, } \\
\text { cyan[o]-) (WE) }\end{array}$ & $\begin{array}{l}\text { Zyanopathie } \\
\text { (Cyanopathia) }\end{array}$ & Blausuchtleiden & & \\
\hline zyto- (zyt-) (WE) & Zytoblast & $\begin{array}{l}\text { Bezeichnung für den } \\
\text { Zellkern }\end{array}$ & Citoblasto & $\begin{array}{l}\text { Célula madre, } \\
\text { blastocito }\end{array}$ \\
\hline
\end{tabular}

Tabla XVII. Constituyentes compositivos en posición prefijal con un sinónimo en el alemán general.

\section{Apéndice II}

\begin{tabular}{|c|c|c|c|c|}
\hline Compuesto & Alemán médico & Alemán general & $\begin{array}{l}\text { Español } \\
\text { médico }\end{array}$ & $\begin{array}{l}\text { Español } \\
\text { médico/general }\end{array}$ \\
\hline alpha- (BW) & Alphawellen & $\begin{array}{l}\text { normale } \\
\text { Wellenform der } \\
\text { Hirnströme }\end{array}$ & Onda alfa & $\begin{array}{l}\text { Ritmo alfa ritmo } \\
\text { de Berger }\end{array}$ \\
\hline beta- (BW) & Betarezeptor & $\begin{array}{l}\text { Rezeptor des } \\
\text { sympathischen } \\
\text { Nervensystems } \\
\end{array}$ & $\begin{array}{l}\text { Receptor } \\
\text { beta }\end{array}$ & Receptor $\beta$ \\
\hline echo- (BW) & Echolalie & $\begin{array}{l}\text { sinnloses, } \\
\text { mechanisches } \\
\text { Nachsprechen } \\
\text { gehörter Wörter }\end{array}$ & Ecolalia & Ecofrasia \\
\hline elektro- (WE) & $\begin{array}{l}\text { Elektrokardiogram } \\
\mathrm{m}\end{array}$ & $\begin{array}{l}\text { Aufzeichnung des } \\
\text { Verlaufs der } \\
\text { Herzaktionsström } \\
\text { e }\end{array}$ & $\begin{array}{l}\text { Electrocardio } \\
\text { grama }\end{array}$ & $\begin{array}{l}\text { Registro } \\
\text { electrocardiográfic } \\
\text { o [Abr23: ECG; con } \\
\text { frecuencia: }\end{array}$ \\
\hline
\end{tabular}

${ }^{23}$ Sigla que utiliza el DTM con el significado de "abreviatura". 


\begin{tabular}{|c|c|c|c|c|}
\hline & & & & "electro"] \\
\hline ergo- (erg-) (WE) & Ergometer & $\begin{array}{l}\text { Apparat zur } \\
\text { Messug der } \\
\text { Arbeitsleistung } \\
\text { von Muskeln }\end{array}$ & Ergómetro & $\begin{array}{l}\text { Aparato para } \\
\text { medir el trabajo } \\
\text { realizado por los } \\
\text { músculos durante } \\
\text { un ejercicio. }\end{array}$ \\
\hline hygro- (BW) & Hygrometer & $\begin{array}{l}\text { Instrument zur } \\
\text { Messung der } \\
\text { Luftfeuchtigkeit }\end{array}$ & & \\
\hline $\begin{array}{l}\text { karyo- (kary-) } \\
\text { (BW) }\end{array}$ & Karyoklasie & $\begin{array}{l}\text { Auseinanderbrech } \\
\text { en des Zellkerns }\end{array}$ & & \\
\hline $\begin{array}{l}\text { kerato- (kerat-) } \\
\text { (BW) }\end{array}$ & Keratolyse & $\begin{array}{l}\text { Auflösung der } \\
\text { Hornschicht der } \\
\text { Epidermis }\end{array}$ & Queratólisis & $\begin{array}{l}\text { Ablandamiento y } \\
\text { disolución de la } \\
\text { capa córnea de la } \\
\text { epidermis }\end{array}$ \\
\hline milli- (BW) & Milliliter & $\begin{array}{l}\text { in der Medizin } \\
\text { statt } \\
\text { Kubikzentimeter } \\
\text { (ccm, cm3) übliche } \\
\text { Bez. für den } \\
\text { tausendsten Teil } \\
\text { eines Liters (Abk.: } \\
\text { ml) }\end{array}$ & Mililitro & $\begin{array}{l}\text { Unidad de } \\
\text { volumen } \\
\text { equivalente a la } \\
\text { milésima parte de } \\
\text { un litro (10-3 l) }\end{array}$ \\
\hline $\begin{array}{l}\text { normo- } \\
\text { (norm-) (BW) }\end{array}$ & Normosomie & $\begin{array}{l}\text { Normalwuchs des } \\
\text { Körpers }\end{array}$ & & \\
\hline pachy- (WE) & $\begin{array}{l}\text { Pachydermie } \\
\text { (Pachydermia) }\end{array}$ & $\begin{array}{l}\text { Verdickung der } \\
\text { Haut, bes. der } \\
\text { Unterhaut }\end{array}$ & Paquidermia & $\begin{array}{l}\text { Hipertrofia y } \\
\text { engrosamiento de } \\
\text { la piel de aspecto } \\
\text { mamelonado y } \\
\text { plegado, que } \\
\text { recuerda al de la } \\
\text { piel de los } \\
\text { elefantes }\end{array}$ \\
\hline $\begin{array}{l}\text { Pneumato- } \\
\text { (pneumat-) (WE) }\end{array}$ & Pneumatometer & $\begin{array}{l}\text { Quecksilbermano } \\
\text { meter zur } \\
\text { Messung des } \\
\text { Luftdrucks }\end{array}$ & & \\
\hline polio- (WE) & Poliomyelitis & $\begin{array}{l}\text { Entzündung der } \\
\text { grauen } \\
\text { Rückenmarksubst } \\
\text { anz }\end{array}$ & Poliomielitis & $\begin{array}{l}\text { Inflamación de la } \\
\text { sustancia gris de la } \\
\text { médula espinal }\end{array}$ \\
\hline $\begin{array}{l}\text { rhachi- (rhachio-, } \\
\text { rachi-, rachio-) } \\
\text { (BW) }\end{array}$ & Rhachialgie & $\begin{array}{l}\text { Schmerz im } \\
\text { Bereich der } \\
\text { Wirbelsäule }\end{array}$ & Raquialgia & $\begin{array}{l}\text { Dolor localizado en } \\
\text { la columna } \\
\text { vertebral }\end{array}$ \\
\hline xero- (xer-) (WE) & Xerodermie & $\begin{array}{l}\text { Trockenheit der } \\
\text { Haut }\end{array}$ & Xerodermia & Piel reseca \\
\hline $\begin{array}{l}\text { zyklo- (zykl-, } \\
\text { cycl[o]-) (WE) }\end{array}$ & Zykloplegie & $\begin{array}{l}\text { Akkomodationsläh } \\
\text { mung des Auges, } \\
\text { insbes. Lähmung } \\
\text { des Ziliarmuskels }\end{array}$ & Cicloplejia & $\begin{array}{l}\text { Parálisis } \\
\text { farmacológica de la } \\
\text { acomodación }\end{array}$ \\
\hline
\end{tabular}


Tabla XVIII. Constituyentes compositivos en posición prefijal con un complemento en genitivo en el alemán general.

\section{Apéndice III}

\begin{tabular}{|c|c|c|c|c|}
\hline Compuesto & $\begin{array}{l}\text { Alemán } \\
\text { médico }\end{array}$ & Alemán general & $\begin{array}{l}\text { Español } \\
\text { médico }\end{array}$ & $\begin{array}{l}\text { Español } \\
\text { médico/general }\end{array}$ \\
\hline astro-(WE) & $\begin{array}{l}\text { Astrozytom } \\
\text { (Astrocytoma) }\end{array}$ & $\begin{array}{l}\text { von Astrozyten } \\
\text { ausgehender Groß- } \\
\text { oder Kleinhirntumor }\end{array}$ & Astrocitoma & Astroglioma \\
\hline brady- (BW) & Bradykardie & $\begin{array}{l}\text { verlangsamte } \\
\text { Herzschlagfolge }\end{array}$ & Bradicardia & Bradirritmia \\
\hline delta- (BW) & Deltawellen & $\begin{array}{l}\text { im } \\
\text { Elektroenzepahlogra } \\
\text { mm auftretende } \\
\text { wellenförmige } \\
\text { Kurven bei einer } \\
\text { Frequenz von 0,5 - } \\
3,5 \mathrm{~Hz}\end{array}$ & Ondas delta & Ritmo $\delta$ \\
\hline gamma- (BW) & $\begin{array}{l}\text { Gamma- } \\
\text { Strahlen (Y- } \\
\text { Strahlen) }\end{array}$ & $\begin{array}{l}\text { kurzwellige, } \\
\text { energiereiche } \\
\text { Strahlung } \\
\text { radioaktiver Stoffe }\end{array}$ & Rayos gamma & RayosY, radiación $Y$ \\
\hline $\begin{array}{l}\text { hypno- (hypn-) } \\
\text { (BW) }\end{array}$ & Hypnalgie & $\begin{array}{l}\text { nur im Schlaf } \\
\text { auftretende } \\
\text { subjektive } \\
\text { Schmerzempfindung }\end{array}$ & & \\
\hline $\begin{array}{l}\text { kako- (kak-) } \\
\text { (BW) }\end{array}$ & Kakogeusie & $\begin{array}{l}\text { übler Geschmack im } \\
\text { Munde }\end{array}$ & & \\
\hline oxy- (WE) & Oxyhämoglobin & $\begin{array}{l}\text { oxidiertes } \\
\text { Hämoglobin }\end{array}$ & $\begin{array}{l}\text { Oxihemoglobin } \\
\text { a }\end{array}$ & $\begin{array}{l}\text { Hemoglobina } \\
\text { oxigenada }\end{array}$ \\
\hline primär- (WE) & Primärtumor & $\begin{array}{l}\text { primarius, } \\
\text { ursprünglicher } \\
\text { Tumor }\end{array}$ & & \\
\hline $\begin{array}{l}\text { tropho- (troph-) } \\
\text { (BW) }\end{array}$ & Trophödem & $\begin{array}{l}\text { auf Störungen der } \\
\text { Gewebsernährung } \\
\text { beruhende, } \\
\text { chronisch } \\
\text { verlaufende, } \\
\text { schmerzlose } \\
\text { Schwellung } \\
\text { besonders der Beine }\end{array}$ & & \\
\hline
\end{tabular}

Tabla XIX. Constituyentes compositivos en posición prefijal con un sintagma nominal formado por uno o varios adjetivos en el alemán general. 


\section{Apéndice IV}

\begin{tabular}{|c|c|c|c|c|}
\hline Prefijo & Alemán médico & Alemán general & $\begin{array}{l}\text { Español } \\
\text { médico }\end{array}$ & $\begin{array}{l}\text { Español } \\
\text { médico/general }\end{array}$ \\
\hline a- (an-, ar-) (V) & $\begin{array}{l}\text { Anämie } \\
\text { (Anaemia) }\end{array}$ & Blutarmut & Anemia & \\
\hline ab- (abs-, a-) (V) & Abusus & Missbrauch & Abuso & \\
\hline $\begin{array}{l}\text { ad- (ac-, af-, ag-, ak-, } \\
\text { al-, an-, ap-, ar-, as-, } \\
\text { at-) (V) }\end{array}$ & adsorbieren & $\begin{array}{l}\text { festhalten (von } \\
\text { Stoffen) }\end{array}$ & Absorber & \\
\hline $\begin{array}{l}\text { amb- (ambi-, am-) } \\
\text { (V) }\end{array}$ & Ambidextrie & Beidhändigkeit & Ambidextrismo & Ambidestreza \\
\hline amphi- (V) & $\begin{array}{l}\text { Amphiarthrose, } \\
\text { Amphiarthrosis }\end{array}$ & Wackelgelenk & Anfiartrosis & $\begin{array}{l}\text { Articulación } \\
\text { cartilaginosa } \\
\text { secundaria }\end{array}$ \\
\hline ana- (an-) (V) & analog & $\begin{array}{l}\text { entsprechend, } \\
\text { übereinstimmend, } \\
\text { ähnlich, gleichartig }\end{array}$ & Analógico & \\
\hline apo- (ap-) (V) & $\begin{array}{l}\text { Aponeurose } \\
\text { (Aponeurosis) }\end{array}$ & $\begin{array}{l}\text { Sehnenhaut, } \\
\text { Sehnenblatt }\end{array}$ & Aponeurosis & $\begin{array}{l}\text { Membrana } \\
\text { aponeurótica }\end{array}$ \\
\hline de- (V) & $\begin{array}{l}\text { Decidua } \\
\text { (Dezidua) }\end{array}$ & Siebhaut & Decidua & $\begin{array}{l}\text { Membrana } \\
\text { caduca, } \\
\text { membrana } \\
\text { decidua }\end{array}$ \\
\hline dia- (di-) (V) & $\begin{array}{l}\text { Diameter } \\
\text { (Diametri) }\end{array}$ & Durchmesser & Diámetro & \\
\hline dis- (dif-, di-) (V) & dispensieren & $\begin{array}{l}\text { Arzneien } \\
\text { zubereiten und } \\
\text { ausgeben }\end{array}$ & Dispensar & Despachar \\
\hline dys- (P) & Dyslexie & Lesestörung & Dislexia & Legastenia \\
\hline en- (em-) (V) & $\begin{array}{l}\text { emboliform } \\
\text { (emboliformis) }\end{array}$ & $\begin{array}{l}\text { pfropfenförmig, } \\
\text { pfropfenartig }\end{array}$ & Emboliforme & \\
\hline endo- (end-) (P) & $\begin{array}{l}\text { Endokard } \\
\text { (Endocardium) }\end{array}$ & Herzinnenhaut & Endocardio & \\
\hline ento- (ent-) (P) & Enthelminthen & Eingeweidewürmer & & \\
\hline epi- (ep-, eph-) (P) & Epidermis & Oberhaut & Epidermis & Cutícula \\
\hline ex- (e-, ef-) (P) & $\begin{array}{l}\text { Excrement } \\
\text { (Excrementum) }\end{array}$ & Körperausscheidung & Excremento & Excreción \\
\hline hetero- (heter-) (P) & heterotherm & $\begin{array}{l}\text { wechselwarm, } \\
\text { kaltblütig }\end{array}$ & & \\
\hline homo- (hom-) (P) & $\begin{array}{l}\text { homolateral } \\
\text { (homolateralis) }\end{array}$ & $\begin{array}{l}\text { gleichseitig (auf der } \\
\text { gleichen Seite) }\end{array}$ & Homolateral & Ipsilateral \\
\hline hyper- (P) & hyperalgetisch & $\begin{array}{l}\text { schmerzüberempfi } \\
\text { ndlich }\end{array}$ & & \\
\hline $\begin{array}{l}\text { hypo- (hyp-, hyph-) } \\
\text { (P) }\end{array}$ & Hypochondrie & Krankheitswahn & Hipocondría & Hipocondriasis \\
\hline
\end{tabular}




\begin{tabular}{|c|c|c|c|c|}
\hline in-1 (il-, im-, ir-) (V) & $\begin{array}{l}\text { Inkarzeration } \\
\text { (Incarceratio) }\end{array}$ & $\begin{array}{l}\text { Einklemmung (bes. } \\
\text { von } \\
\text { Eingeweideteilen in } \\
\text { einem Bruchsack) }\end{array}$ & Incarceración & Encarcelamiento \\
\hline in-2 (il-, im- ir-) (V) & impotent & $\begin{array}{l}\text { beischlafsunfähig; } \\
\text { zeugungsunfähig }\end{array}$ & Impotente & \\
\hline inter- $(P)$ & intermediär & dazwischenliegend & Intermediario & Mediador \\
\hline intro- $(P)$ & Introspektion & $\begin{array}{l}\text { Innenschau, } \\
\text { Selbstbetrachtung }\end{array}$ & Introspección & Autoanálisis \\
\hline iso- (is-) (P) & Isokorie & Pupillengleichheit & Isocoria & Pupilas iguales \\
\hline $\begin{array}{l}\text { kon- (kom-, kol-, } \\
\text { kor-, ko-, con-, co-, } \\
\text { col-, com-, cor-) (P) }\end{array}$ & $\begin{array}{l}\text { konfluent } \\
\text { (confluens) }\end{array}$ & $\begin{array}{l}\text { zusammenfließend, } \\
\text { sich vereinigend }\end{array}$ & Confluyente & Confluente \\
\hline kontra- (P) & $\begin{array}{l}\text { Kontrazeption } \\
\text { (Contraceptio) }\end{array}$ & $\begin{array}{l}\text { Empfängnisverhütung } \\
\text { ' } \\
\text { Befruchtungsverhütu } \\
\text { ng }\end{array}$ & Contracepción & Anticoncepción \\
\hline meta- (met-) (P) & Metacarpus & Mittelhand & Metacarpo & \\
\hline metro- (metr-) (P) & Metromanie & Nymphomanie & & \\
\hline mono- (mon-) (P) & Monosacharid & Einfachzucker & Monosacárido & \\
\hline multi- (P) & $\begin{array}{l}\text { multizellulär } \\
\text { (multicellularis) }\end{array}$ & vielzellig & Multicelular & Pluricelular \\
\hline $\begin{array}{l}\text { ob- (oc-, ok-, of-, } \\
\text { op-) (P) }\end{array}$ & Obduktion & Leichenöffnung & & \\
\hline osteo- (oste-) (P) & Ostealgie & Knochenschmerz & Ostealgia & Dolor óseo \\
\hline para- (par-) (P) & Parodontose & Zahnfleischschwund & & \\
\hline peri- $(\mathrm{P})$ & $\begin{array}{l}\text { Perikard } \\
\text { (Pericardium) }\end{array}$ & Herzbeutel & Pericardio & Saco pericárdico \\
\hline $\begin{array}{l}\text { pneumo- } \\
\text { (pneumono, } \\
\text { pneum-, pneumon- } \\
\text { (P) }\end{array}$ & $\begin{array}{l}\text { Pneumokoniose } \\
\text { (Pneumoconiosis } \\
\text { ) }\end{array}$ & Staublunge & $\begin{array}{l}\text { Pneumoconiosi } \\
\mathrm{s}= \\
\text { Neumoconiosis }\end{array}$ & \\
\hline post- $(\mathrm{P})$ & Postmolar & Mahlzahn & & \\
\hline pro- $(\mathrm{P})$ & $\begin{array}{l}\text { Prolaps } \\
\text { (Prolapsus) }\end{array}$ & Vorfall & Prolapso & Procidencia \\
\hline proso- (pros-) (P) & $\begin{array}{l}\text { Prosencephalon } \\
\text { (Prosenzephalon) }\end{array}$ & Vorderhirn & Prosencéfalo & Cerebro anterior \\
\hline re- $(P)$ & Recessus & $\begin{array}{l}\text { Vertiefung, Mulde, } \\
\text { Einbuchtung }\end{array}$ & Receso & \\
\hline $\begin{array}{l}\text { sub- (suc-, suf-, } \\
\text { sug-, suk, sup, sur-) } \\
\text { (P) }\end{array}$ & Subkutis & $\begin{array}{l}\text { Unterhaut, } \\
\text { Unterhautzellgewebe }\end{array}$ & & \\
\hline super- $(P)$ & $\begin{array}{l}\text { Superfetation } \\
\text { (Superfetatio) }\end{array}$ & Überfruchtung & Superfetación & \\
\hline syn- (sym-, syl-, sy-) & Syndesmose & Bandhaft & Sindesmosis & Articulación \\
\hline
\end{tabular}




\begin{tabular}{|c|c|c|c|c|}
\hline (P) & (Syndesmosis) & & & $\begin{array}{l}\text { sindesmótica, } \\
\text { sínfisis fibrosa }\end{array}$ \\
\hline tele- (tel-) (P) & $\begin{array}{l}\text { Telencephalon } \\
\text { (Telenzephalon) }\end{array}$ & Endhirn & Telencéfalo & $\begin{array}{l}\text { Vesícula } \\
\text { telencefálica }\end{array}$ \\
\hline $\begin{array}{l}\text { trans- (tran-, tra-) } \\
(\mathrm{P})\end{array}$ & Transpiration & $\begin{array}{l}\text { Hautausdünstung, } \\
\text { Schwitzen }\end{array}$ & Transpiración & Sudor \\
\hline ultra- (P) & ultravisibel & unsichtbar & & \\
\hline uni- $(P)$ & unilokulär & einkammerig & Unilocular & Monolocular \\
\hline uro- (ur-) (P) & Urolithiasis & Harnsteinleiden & Urolitiasis & $\begin{array}{l}\text { Cálculos urinarios } \\
\text { [Coloq.: piedras } \\
\text { en la orina] }\end{array}$ \\
\hline
\end{tabular}

Tabla XX. Prefijos con un sinónimo en el alemán general.

\section{Apéndice V}

\begin{tabular}{|c|c|c|c|c|}
\hline Compuesto & $\begin{array}{l}\text { Alemán } \\
\text { médico }\end{array}$ & Alemán general & $\begin{array}{l}\text { Español } \\
\text { médico }\end{array}$ & $\begin{array}{l}\text { Español } \\
\text { médico/general }\end{array}$ \\
\hline -algie (WE) & $\begin{array}{l}\text { Gastralgie } \\
\text { (Gastralgia) }\end{array}$ & $\begin{array}{l}\text { Magenschmerzen, } \\
\text { Magenkrampf }\end{array}$ & Gastralgia & Dolor estomacal \\
\hline -ämie (-hämie) (WE) & $\begin{array}{l}\text { Leukämie } \\
\text { (Leucaemia) }\end{array}$ & $\begin{array}{l}\text { Weißblütigkeit, } \\
\text { Blutkrebs }\end{array}$ & Leucemia & Leucosis \\
\hline $\begin{array}{l}\text {-ämisch (-hämisch, } \\
\text {-[h]aemicus) (GW) }\end{array}$ & ischämisch & blutleer & Isquémico & \\
\hline -blast (GW) & Odontoblast & Zahnbeinbildner & Odontoblasto & Dentinoblasto \\
\hline -dermie (WE) & $\begin{array}{l}\text { Sklerodermie } \\
\text { (Sclerodermia) }\end{array}$ & Darrsucht & Esclerodermia & Dermatoesclerosis \\
\hline -fizieren (WE) & mumifizieren & $\begin{array}{l}\text { eintrocknen, } \\
\text { absterben lassen }\end{array}$ & Momificar(se) & $\begin{array}{l}\text { Convertir(se) un } \\
\text { cadáver en momia }\end{array}$ \\
\hline -iater (WE) & Pädiater & Kinderarzt & Pediatra & \\
\hline -iatrie (WE) & Geriatrie & Altersheilkunde & Geriatría & $\begin{array}{l}\text { Gerontología } \\
\text { clínica }\end{array}$ \\
\hline -klast (GW) & Osteoklast & Knochenfresszellen & Osteoclasto & Célula osteoclástica \\
\hline -lith (GW) & Cholelith & Gallenstein & & \\
\hline -loge (WE) & Ophthalmologe & Augenarzt & Oftalmólogo & Oculista \\
\hline -logie (WE) & Nosologie & Krankheitslehre & Nosología & \\
\hline -logisch (GW) & toxikologisch & $\begin{array}{l}\text { giftkundig, } \\
\text { giftsachverständig }\end{array}$ & Toxicológico & \\
\hline -lyse (WE) & Lipolyse & Fettspaltung & Lipólisis & $\begin{array}{l}\text { Adipólisis, } \\
\text { lipoclasia }\end{array}$ \\
\hline -manie (WE) & Mikromanie & Kleinheitswahn & & \\
\hline
\end{tabular}




\begin{tabular}{|c|c|c|c|c|}
\hline -metrie (WE) & Zephalometrie & Schädelmessung & Cefalometría & Craneometría \\
\hline -pathie (WE) & Gastropathie & Magenleiden & Gastropatía & $\begin{array}{l}\text { Enfermedad } \\
\text { estomacal }\end{array}$ \\
\hline -pathisch (WE) & $\begin{array}{l}\text { idiopathisch } \\
\text { (idiopathicus) }\end{array}$ & selbständig, primär & Idiopático & $\begin{array}{l}\text { Criptogénico, } \\
\text { esencial, primario }\end{array}$ \\
\hline -phagie (GW) & Koprophagie & Kotessen & Coprofagia & Cacofagia \\
\hline -philie (WE) & Hämophilie & Bluterkrankheit & Hemofilia & \\
\hline -phob (WE) & fotophob & $\begin{array}{l}\text { lichtscheu, - } \\
\text { empfindlich }\end{array}$ & Fotófobo & Fotofóbico \\
\hline -phobie (WE) & Fotophobie & Lichtscheu & Fotofobia & Fotosensibilidad \\
\hline -phonie (GW) & Ägophonie & $\begin{array}{l}\text { Meckerstimme, } \\
\text { Ziegenmeckern }\end{array}$ & Egofonía & \\
\hline -phyt (GW) & Dermatophyt & Hautpilz & Dermatofito & Hongo dermatófilo \\
\hline -skop (WE) & Rhinoskop & Nasenspiegel & Rinoscopio & Nasofaringoscopio \\
\hline -som (WE) & leptosom & $\begin{array}{l}\text { schmal-, } \\
\text { schlankwüchsig, } \\
\text { schmalgesichtig } \\
\end{array}$ & leptosómico & asténico \\
\hline -somie (WE) & Makrosomie & Gigantismus & Macrosomía & Gigantismo \\
\hline -therm (WE) & homöotherm & $\begin{array}{l}\text { gleichwarm, } \\
\text { warmblütig }\end{array}$ & Homeotérmico & Endotérmico \\
\hline $\begin{array}{l}\text {-tomie (-tomia) } \\
\text { (WE) }\end{array}$ & Anatomie & Zergliederungskunst & Anatomía & \\
\hline -trophie (WE) & $\begin{array}{l}\text { Dystrophie } \\
\text { (Dystrophia) }\end{array}$ & Ernährungsstörung & Distrofia & \\
\hline -urie (WE) & Phenylketonurie & Fölling-Krankheit & Fenilcetonuria & $\begin{array}{l}\text { Oligofrenia } \\
\text { fenilpirúvica [Abr.: } \\
\text { FCU, PKU] }\end{array}$ \\
\hline
\end{tabular}

Tabla XXI. Constituyentes compositivos en posición sufijal con un sinónimo en el alemán general.

\section{Apéndice VI}

\begin{tabular}{lllll}
\hline Compuesto & $\begin{array}{l}\text { Alemán } \\
\text { médico }\end{array}$ & Alemán general & $\begin{array}{l}\text { Español } \\
\text { médico }\end{array}$ & $\begin{array}{l}\text { Español } \\
\text { médico/general }\end{array}$ \\
\hline
\end{tabular}




\begin{tabular}{lllll}
\hline -ergisch (GW) & adrenergisch & durch Adrenalin bewirkt & Adrenérgico & Catecolaminérgico \\
\hline -gam (WE) & metagam & $\begin{array}{l}\text { nach der Befruchtung } \\
\text { erfolgend }\end{array}$ & & \\
\hline -man (WE) & nymphoman & $\begin{array}{l}\text { an Nymphomanie } \\
\text { leidend }\end{array}$ & Ninfómano & \\
\hline -mane (WE) & Monomane & $\begin{array}{l}\text { an Monomanie } \\
\text { Leidende[r] }\end{array}$ & & \\
\hline -metrisch (GW) & spirometrisch & $\begin{array}{l}\text { mithilfe der Spriometrie } \\
\text { erfolgend }\end{array}$ & Espirométrico & Respirométrico \\
\hline -phag (GW) & bakteriophag & $\begin{array}{l}\text { Bakterien vertilgend, } \\
\text { tötend }\end{array}$ & & \\
\hline -phil (WE) & pädophil & $\begin{array}{l}\text { auf Pädophilie } \\
\text { beruhend }\end{array}$ & Pedófilo & Pederasta \\
\hline -trop (GW) & gonadotrop & $\begin{array}{l}\text { auf die Keimdrüsen } \\
\text { einwirkend }\end{array}$ & Gonadótropo & Que tiene afinidad \\
& dystroph & mangelhaft ernährt & Distrófico & \\
\hline -troph (WE) & (dystrophisch) & pónadas \\
\hline
\end{tabular}

Tabla XXII. Constituyentes compositivos en posición sufijal con un sintagma formado por un participio de presente o de pasado en el alemán general.

\section{Apéndice VII}

\begin{tabular}{|c|c|c|c|c|}
\hline Sufijo & Alemán médico & Alemán general & $\begin{array}{l}\text { Español } \\
\text { médico }\end{array}$ & $\begin{array}{l}\text { Español } \\
\text { médico/general }\end{array}$ \\
\hline -abel (S) & variabel (variabilis) & veränderlich & Variable & Variante \\
\hline -and (-ant) (S) & Querulant & Nörgler, Quengler & & \\
\hline \multirow{2}{*}{$\begin{array}{l}\text {-ation/-ierung } \\
\text { (S) }\end{array}$} & Reanimation & Wiederbelebung & Reanimación & \\
\hline & Vakzinierung & Impfung & Vacunación & Vacunoterapia \\
\hline -gen (S) & Kollagen & Leimbildner & Colágeno & \\
\hline -id (E) & $\begin{array}{l}\text { adenoid } \\
\text { (adenoides, } \\
\text { adenoideus) }\end{array}$ & drüsenähnlich & Adenoide & $\begin{array}{l}\text { Adeniforme, } \\
\text { glanduliforme }\end{array}$ \\
\hline -itis (E) & Tonsillitis & Mandelentzündung & Tonsilitis & $\begin{array}{l}\text { Amigdalitis } \\
\text { [Coloq.: anginas] }\end{array}$ \\
\hline -meter (S) & Thermometer & Temperaturmessgerät & Termómetro & \\
\hline -odynie $(\mathrm{N})$ & Achillodynie & Fersenschmerz & Aquilodinia & \\
\hline -om / -oma (S) & $\begin{array}{l}\text { Karzinom } \\
\text { (Carcinoma) }\end{array}$ & Krebsgeschwulst & Carcinoma & Cáncer [Abr.: Ca] \\
\hline
\end{tabular}




\begin{tabular}{lllll}
\hline -osis /-ose (S) & $\begin{array}{l}\text { Pedikulose } \\
\text { (Pediculosis) }\end{array}$ & Läusebefall & Pidiculosis & [Coloq.] piojos \\
\hline -zele (S) & Zephalozele & Kopfbruch & Cefalocele & Cavidad craneal \\
\hline
\end{tabular}

Tabla XXIII. Sufijos con un sinónimo en el alemán general. 